\title{
Die Geburt der Zukunftsangst
}

\section{Politics of fear}

Am 20. März 2003 griff die «Koalition der Willigen» unter der Führung der USA den Irak an. Begründet wurde die Militärinvasion mit der Existenz von Massenvernichtungswaffen im Irak - eine Begründung, die international so umstritten war, dass der damalige US-amerikanische Präsident George W. Bush sich gezwungen sah, den Angriff ohne Resolution der Vereinten Nationen und trotz Veto von drei Mitgliedern des Sicherheitsrats zu befehlen. Nach dem zweiten Irakkrieg erwies sich die Begründung zudem als falsch.

An einer Pressekonferenz im Vorfeld des Krieges nahm der damalige USVerteidigungsminister Donald Rumsfeld Stellung zur angeblichen Existenz von Massenvernichtungswaffen. Statt Beweise vorzulegen, antwortete er mit einer Art Theorie des Unwissens, die dem Publikum klarmachen sollte, dass sich die USA selbst auf die uunbekanntesten〉 aller unbekannten Gefahren vorbereite:

«[...] as we know, there are known knowns; there are things we know we know. We also know there are known unknowns; that is to say we know there are some things we do not know. But there are also unknown unknowns - the ones we don't know we don't know. And if one looks throughout the history of our country and other free countries, it is the latter category that tend to be the difficult ones [sic].» (Rumsfeld 2002; eigene Hervorhebung)

Es wird gemunkelt, dass Nassim Taleb, der Finanzmathematiker, dessen Buch The Black Swan. The Impact of the Highly Improbable (2007) zum Weltbestseller wurde, Rumsfeld kurz vor der fraglichen Pressekonferenz mit seinen Ideen über unwahrscheinliche, aber schwerwiegende Ereignisse nachhaltig inspiriert habe (Burkeman 2007).

Rumsfelds unknown unknowns verbreiteten sich viral und zogen Tausende von Kommentaren auf sich. Slavoj Žižek, der umtriebige Philosoph aus Ljubljana, machte etwa auf die Unvollständigkeit von Rumsfelds Theorie aufmerksam, da dieser die vierte Option, nämlich die unknown knowns vergessen habe - eine Option, auf die es aber in seiner Analyse moderner Ideologie ankomme. 
Tatsächlich lohnt es sich, Rumsfelds unbekannten Unbekannten etwas Aufmerksamkeit zu schenken. Einerseits lassen sie sich als Symptom einer zugespitzten Chronopolitik lesen, mit der wir auf die noch unwahrscheinlichsten Zukunftsunfälle heute schon reagieren. ${ }^{1}$ Üblicherweise sind es mehr oder minder wahrscheinliche Krisen in der Zukunft, die uns veranlassen, die Gegenwart zu korrigieren. Zu diesen Bedrohungslagen gehören Szenarien wie die Überalterung der Gesellschaft, der Klimawandel oder technologische Fernfolgen. Diese und ähnliche Risiken werden im Rahmen chronopolitischen Reagierens auf die Zukunft regelmässig zu future facts gehärtet, die die Notwendigkeit und Dringlichkeit politischen Handelns vor Augen führen sollen. All das ist schon denkwürdig genug. An Rumsfelds unknown unknowns aber ist unerhört, dass sie eine unerkennbare Bedrohungslage in Gestalt frei erfundener Massenvernichtungswaffen im Irak zum Kriegsgrund erhoben haben. Wahrscheinlich zum ersten Mal in der Geschichte hat ein Land ein anderes im Namen des Hochunwahrscheinlichen - im Namen von the Highly Improbable - angegriffen und dies mithilfe eines "preemptive strike» (Bush 2002). In dubio pro bello.

Andererseits dürfen diese bis ins Noumenale gesteigerten Ungewissheiten, wie sie in Rumsfelds unknown unknowns zum Ausdruck kommen, als Anhaltspunkte für eine politische Epistemologie des Unwahrscheinlichen gelten, die inzwischen von etlichen sozial- und geisteswissenschaftlichen Studien registriert wird. Das Buch Speculative Security (Goede 2012) diagnostiziert eine sich formierende Logik des Regierens, die sich zunehmend von ungewissen $\mathrm{Zu}$ künften gefangen nehmen lässt. Life as Surplus (Cooper 2008) bestätigt diesen Befund, indem es die zunehmende Bedeutung von desaströsen, aber unwahrscheinlichen Risiken als Keimzelle für eine neue Biopolitik in Michel Foucaults Sinn begreift (Stichwort Anthrax). Selbst in einem Sammelband mit dem unverfänglichen Titel Environmental Security kommen spezifische Beiträge nicht umhin, den Einfluss einer Politik, die sich der Bewältigung unwahrscheinlicher, doch katastrophaler Gefahren verschrieben hat, auf das ökologische Denken festzuhalten (u. a. Watts 2013).

Etwas abseits der Aktualität dieser Studien sind Bände erschienen, die sich mit der anthropologischen Grundlage dieser Epistemologie des Unwahrscheinlichen auseinandersetzen: der Angst. Sie wird historisch und politisch als Fähigkeit vertieft, die Zukunft im Lichte der Gefahr zu sehen oder,

1 Chronopolitik bezeichnet das Reagieren auf bedrohliche Zukünfte. Das Ziel besteht in einer Korrektur der Gegenwart, damit sie keinen Anlass für eine künftige Katastrophe mehr bietet (Kaiser 2015). 
sofern es um Politik geht, heraufzubeschwören. Der Sammelband Facing Fear: The History of an Emotion in Global Perspective (Laffan/Weiss 2012) erhellt verschiedene Episoden einer Geschichte der Angst etwa in der Weimarer Republik, dem faschistischen Italien oder dem zeitgenössischen Indien. Überaus lesenswert, provokativ und materialreich präsentiert sich Fear: The History of a Political Idea (Robin 2004). Von Hobbes bis heute arbeitet es zunächst die Geschichte der politischen Theorie und deren Reflexionen zur Angst auf, wendet sich dann der politischen Instrumentalisierung der Angst in der jüngeren Geschichte Amerikas zu und wagt schliesslich ein Resümee: Angst kann und darf Legitimationsquelle einer liberalen Politik weder sein noch werden. Zu einem ähnlichen Schluss gelangt The Politics of Fear (Wodak 2015), das die rhetorischen und politischen Angstbeschwörungen rechter Parteien und rechtsextremer Bewegungen analysiert.

Sicherlich, die enorme Sensibilität gegenüber «schwarzen Schwänen»höchst unwahrscheinlichen, aber möglicherweise katastrophalen Ereignissen - lässt sich kaum ohne die spezifische Fähigkeit der Angst erklären, für die Zukunft schwarzzusehen. Nur, die erwähnten Bücher verstehen Angst als historisch invarianten Rohstoff, mit dem in der Geschichte mal mehr, mal weniger Politik gemacht wurde. Die Angst gerät damit zu einer anthropologischen Konstante oder einer invarianten Ressource, die immer schon da ist. Zwar künden die Buchtitel nicht selten eine Geschichte der Angst an, doch bei genauerem Hinsehen erweist sich das Gegenteil: Alle anderen - die Politik, die Literatur, die Theorie oder die Gesellschaft - haben eine Geschichte, nur die Angst nicht. Nicht nur ist die Angst diachron stets mit sich selbst identisch, auch synchron bleibt sie differenzlos. Zwischen Sozial-, Existenzoder Zukunftsängsten etwa wird nicht unterschieden. Das ist insofern bedauerlich, als damit eine Lücke in der Deutung der jüngeren Angstüberbietung, wie sie in Rumsfelds unknown unknowns sich artikuliert, zutage tritt. Die politische Epistemologie des Unwahrscheinlichen, wie sie in den zeitdiagnostischen Studien en détail nachgezeichnet wird, findet in einer Geschichte der Angst noch keine Entsprechung. Angst, so lehren uns die historischen Werke, ist zwar eine Antwort auf die Frage, wie sich eine Sensibilität gegenüber den dunklen Seiten der Zukunft entwickeln konnte. Allerdings ist sie so unspezifisch, dass sie nahezu jedes politische Agieren erklärt, das sich konservativ gegen Veränderung stemmt. Die These, die ich in meinem Aufsatz zu plausibilisieren suche, rückt eine historisch gewachsene Zukunftsangst als Grund für unsere Sensibilitäten gegenüber unwahrscheinlichen Gefahren ins Blickfeld. Diese Angst, so die zweite These, ist das Produkt eines allmählichen Ausdifferenzierungsprozesses, der am Ende des 18. Jahrhunderts als 
Reaktion auf die Erfindung und Entdeckung einer offenen Zukunft begonnen hat und sich besonders an der Kontingenz der Zukunft als «Möglichkeit für die Möglichkeit» (Kierkegaard) abarbeitet.

Behauptet wird also erstens, dass die Angst selbst eine Geschichte hat; zweitens, dass im 20. Jahrhundert aus der Angst eine Zukunftsangst hervorgegangen ist, und drittens, dass diese Angst das chronopolitische Zeitalter grundiert - ein Zeitalter also, in dem mehr denn je auf problematische Zukünfte reagiert wird, oft mit einschneidenden Korrekturen der Gegenwart.

\section{Eine historische Ontologie der Angst}

Wie lässt sich eine Geschichte der Angst in Angriff nehmen, wenn diese Befindlichkeit zum Menschsein gehört wie Freude oder Trauer? Was wäre gar, wenn Angst nicht nur Menschen, sondern auch Säugetieren eigen ist? Eine Geschichte der Angst wäre so eine Evolutionsgeschichte, die kaum auf kulturelle Veränderungen binnen wenigen Jahrzehnten reagieren könnte.

\subsection{Die Angst als Monster}

Beginnen wir mit einer Irritation: Die Angst gleicht einem Monster. Sie zeigt sich erstens unmittelbar, zweitens ist sie hybride und drittens macht sie bewusst, was normal wäre. Mit diesen drei Merkmalen, die Jacques Derrida zur Charakterisierung eines Monsters verwendet hat, lässt sich eine Analytik in Gang bringen, welche die Angst als irreduzibles Phänomen von gewissen Tieren und Menschen ernst nimmt, zugleich aber ihre Verstrickung in Kultur und Gesellschaft, wenigstens jener der Menschen, anerkennt. Angst ist, mit anderen Worten, eine emotionale Grundkategorie, die aber dank ihres Sinnbezugs kulturellen und gesellschaftlichen Veränderungen unterworfen ist. Nicht nur das Wovor der Angst, sondern auch das Wie des Sichängstigens unterliegt dem historischen Wandel. Die Angst hat, so die These, eine Geschichte, die weit feinmaschiger ist als jene der biologischen Evolution des Menschen - eine Geschichte, die selbst in der späten Neuzeit die Angst noch zu immer neuen Ausprägungen und Ausgestaltungen zwingt.

Die Angst ist erstens ein Monster, weil sie sich unmittelbar zeigt. Sie ist ein derart «ontologisches» Gefühl, dass sie wie ein eigenes Wesen anmutet. Sie ist ein Geschöpf, das mit uns zur Welt gekommen ist: «Und meine Mutter gebar Zwillinge: mich und die Angst zugleich», schreibt Thomas Hobbes (1839) in seiner Autobiografie. Die Angst ist möglicherweise das Phänomen schlechthin - ein Phänomen, das sich ohne Vermittlung von Sprache, Kultur und Politik reigt: «Angst braucht keine Definition. Sie ist ein grundlegendes 
und sozusagen subpolitisches Gefühl», räsonniert Raymond Aron (1968, 20; Übersetzung M. K.) in seiner Auseinandersetzung mit Montesquieu. Die Angst zeigt sich in ihrer ganzen Fremde, die niemals eine Vertrautheit mit ihr zulässt. Selbst wenn sie einen tagtäglich heimsucht, bleibt sie doch ein fremder Gast.

«Monstren sind Lebewesen. Ausserdem ist das Monstrum etwas, das zum ersten Mal auftaucht und folglich noch nicht erkannt oder wiedererkannt werden kann. [...] [Die Gatung Monstrum] reigt sich einfach [elle se montre] - das ist die Bedeutung des Wortes «Monstrum>-, [es] zeigt sich in einem Wesen, das sich noch nicht gezeigt hatte und deshalb einer Halluzination gleicht, ins Auge fällt, Erschrecken auslöst, eben weil keine Antizipation bereit stand, diese Gestalt zu identifizieren.» (Derrida 2002, 390)

Obwohl ihr Auftreten eine Begegnung mit dem Fremden ist, nimmt die Angst Teil an unserem Geistes- und Gesellschaftsleben.

Zweitens ist die Angst ein Monster, weil sie hybride ist. Sie ist mit Sinn und Bedeutung untrennbar verbunden. Sie lässt sich von Diskursen, Politiken und Strukturen evozieren, sie lässt sich durch ruhiges Zureden besänftigen, sie kann in Märchen erlernt und in langen Gesprächssitzungen allmählich bewältigt werden. Mit anderen Worten, Angst ist im Gegensatz zu Hunger und Durst ungleich kognitiver. Sie ist mitnichten nur ein physiologischer Stimulus, sondern zutiefst verankert in unseren Interpretationen und Wertungen der Welt. Allein die Erzählung einer beängstigenden Situation vermag Ängste vergleichbar jenen zu evozieren, die in dieser Situation realiter durchlebt würden.

Nicht alle, doch viele Abkömmlinge der Angst besitzen eine ganz konkrete Bedeutung bzw. einen spezifischen intentionalen Gehalt. Besonders die Spielarten der Furcht sind alles andere als sinn- und gehaltfrei. Man fürchtet sich vor Spinnen, vor Blut oder vor dem Elfmeterschiessen. Wie und in welchem Umfang die Angst allerdings an diesen sinnbildenden und bedeutungsgebenden Prozessen partizipiert, lässt sich kaum für alle Ängste verallgemeinern und beziffern. Die Angst ist an Sinn und Bedeutung, an Sprache und Kultur, will man kybernetisches Vokabular hier verwenden, nur lose gekoppelt. Sie lässt sich durch Sinnprozesse irritieren, nicht aber determinieren. In vielen Fällen entscheidet die individuelle Biografie darüber, ob und wie kollektive Ängste den Weg zum Subjekt finden. Trotzdem bleibt es dabei: Unsere Ängste hängen wie andere Emotionen von unseren Interpretationen, Wertungen und Deutungen ab. Und diese wiederum leben und sterben mit der Geschichte unserer Gesellschaften. 
Diese kaum quantifizierbare Hybridisierung und Vermengung mit Sinn ist neben ihrer demonstrativen Phänomenalität das zweite Merkmal, das die Angst zu einem Monster macht.

«Ein Monstrum, das kann selbstverständlich eine aus mehreren verschiedenartigen Organismen zusammengesetzte Gestalt sein, deren Bestandteile aufeinander gepfropft wurden. Dieser Pfropfen, diese Hybridisierung, dieses Zusammensetzen verschiedenartiger Körper kann ein Monstrum genannt werden.» (Derrida 2002, 390)

Immerhin erlaubt es diese aufgepfropfte Bedeutung, die Angst für die interpretierenden Wissenschaften wie jene der verstehenden Soziologie zu öffnen - was seit Norbert Elias' Studien zum Prozess der Zivilisation auch geschehen ist. In diese Forschungstradition reiht sich der Beitrag mit der These ein, dass die Angst sich entlang dreier Dimensionen in verschiedene Ängste ausdifferenziert hat:

a) In der sachlichen Dimension hat die Angst sich in verschiedene Varianten der Furcht bzw. in Phobien aufgespreizt.

b) In der sozialen Dimension ist die Angst hingegen vorwiegend in Gestalt von Scham und Scheu vertreten.

c) In der zeitlichen Dimension ist die Angst zur Ungewissheit, ja Zukunftsangst erwachsen.

Furcht, Scham und Zukunftsangst sind also die Kinder der Angst, die diese im Laufe der Jahrhunderte zur Welt gebracht hat.

Die Angst ist letztlich ein Monster, da ihr Auftritt uns bewusst macht, dass etwas unheimlich, befremdlich und abnormal ist. Ihr Befremden ruft uns die fehlende Norm, die unterbrochene Kontinuität oder die verletzte Ordnung in Erinnerung. Die Angst verweist hier nicht nur auf sich selbst, sondern bringt eine Anomie, Entbettung oder Nichtordnung zu Bewusstsein. Exakt diese anzeigende Verbindung zu einem verlorenen Nomos, einer durcheinandergeratenen Gesellschaft oder einem zerstörten Ordnungsgaranten macht eine Geschichte der Angst möglich:

«In solchen Momenten kann die Monstrosität ans Licht oder ins Bewusstsein bringen, was die Normalität ist; vor einem Monstrum wird man sich der Norm bewusst, und wenn diese Norm eine Geschichte hat - was zum Beispiel für die diskursiven, philosophischen, soziokulturellen Normen gilt: sie haben eine Geschichte -, dann erlaubt jedes Erscheinen von Monstrosität in diesem Bereich eine Analyse der Geschichte der Normen.» (Derrida 2002, 390) 
Im Folgenden wird eine Geschichte der Angst erprobt, genauer: eine Geschichte der Zeit- bzw. Zukunftsangst. Es handelt sich hierbei um eine modernitätstheoretisch inspirierte Erzählung über die Entstehung einer zeitlich differenzierten oder spezialisierten Form von Angst.

Um die Geschichte der Zukunftsangst in eine erzählbare Form zu bringen, hilft vorerst ein Blick auf die Gegenwart. Er offenbart eine schier endlose Zahl Ängste, die vermeintlich oder leibhaftig unser Leben heimsuchen. $\mathrm{Ob}$ die in Zeitdiagnosen, Lebenshilferatgebern oder psychotherapeutischen Handbüchern postulierten oder identifizierten Angsttypen de facto existieren, ist nicht Gegenstand des Forschungsinteresses, wohl aber der Befund, dass Diskurse und Strukturen es fertiggebracht haben, die Ängste in allen Sinndimensionen zu vervielfältigen. Sie alle, und darin besteht die theoretische These, die die Erzählung steuert, werden als das Resultat eines Ausdifferenzierungsprozesses begriffen, der die Angst ergriffen und im Laufe der Zeit in Sach-, Sozial- und Zeitängste auseinandergefaltet hat.

Das Theorem einer Ausdifferenzierung der Angst ist, sofern es um die Herausbildung von Sozialphobien geht, nicht neu. Seit Norbert Elias’ Über den Prozess der Zivilisation liegt der Vorschlag für eine Gesellschaftstheorie und -geschichte vor, der das Verhältnis von Individuum und Gesellschaft einerseits historisiert, andererseits, und wichtiger noch, anhand von Veränderungen begreift, die dem Menschen nicht äusserlich in Form von Zwang oder Unterdrückung begegnen, sondern zutiefst in seine Persönlichkeitsstruktur hineinreichen. Das gesamte Trieb- und Affektleben des Menschen erfährt über die Jahrhunderte eine zunehmende Zivilisierung, für die eine Verlagerung von Fremd- zu Selbstzwang kennzeichnend ist. Von diesem Prozess bleibt die Angst nicht verschont. Sie kommt zunehmend im Gefühl der Scham zum Ausdruck, die ein genuin soziales Phänomen darstellt: Scham ist die Angst vor sozialer Degradierung. Als solche operiert sie als vorauseilender Gehorsam gegenüber Machtstrukturen, die jedoch nicht als solche, sondern als verinnerlichte moralische Gebote wahrgenommen werden.

\subsection{Quellen der Angst}

Elias' Studie zur Ausdifferenzierung der Scham dient als Schablone, um die Herausbildung der Zeit- bzw. Zukunftsangst nach der Französischen Revolution nachzuzeichnen. Das ermöglicht eine historische Skizze, die sich vorwiegend als eine philosophische Begriffsgeschichte zu erkennen gibt. Ihre Quellen sind mitunter gut bekannte Texte: Kierkegaards Der Begriff Angst (1844), Freuds Hemmung, Symptom und Angst (1926) oder Heideggers Sein und Zeit (1927). Es sind dies Texte, die die Angst nicht nur explizit als Begriff 
führen, sondern sie zu verstehen, zu deuten und zu interpretieren suchen. Diese Einschränkung der Quellen auf einen sattsam bekannten Philosophiekanon hat zwei Gründe.

Der erste besteht in einer Absenz von Texten, die jenseits des Bemühens, der Angst theoretisch Herr zu werden, praktische Hinweise zur Bewältigung der Zukunftsangst geben. Norbert Elias standen für seine Untersuchungen Manierenbücher zur Verfügung, mit deren Hilfe er die sozialen Strukturen der höfischen Gesellschaft und des Bürgertums rekonstruieren konnte Werke also, die das Subjekt en détail instruieren, in einer bestimmten Gesellschaft zu leben. Die Geschichte einer Ausdifferenzierung von Zeitangst kann sich erst auf Texte stützen, die Akteuren konkrete Handlungsangebote machen, wie sie ihre Zeit- bzw. Zukunftsängste zu rationalisieren haben. Wenngleich Freud die Zukunftsangst unter dem Namen der neurotischen Angst schon am Ende des 19. Jahrhunderts an Patienten feststellen konnte, behandelte er diese jedoch nicht spezifisch, sondern als neurotisch oder phobisch erkrankte Menschen. Erst in den 1970er-Jahren tauchen Dokumente auf, die mit der Zukunftsangst umzugehen wissen. Politisch raten philosophische Traktate dieser Zeit auf einmal dazu, die Zukunftsangst nicht mehr zu ignorieren, sondern sie, wie Hans Jonas (1984 [1979]) fordert, in Form einer «Heuristik der Furcht» gar zu pflegen. Günther Anders, Jacques Ellul, Martin Heidegger, Max Horkheimer und Theodor W. Adorno raten fast zeitgleich zu einer ähnlichen Haltung und legen damit die Grundfesten für eine Chronopolitik, die schon bald danach beginnen wird, die Gegenwart aus der Zukunft heraus zu regieren. All das entzündet sich zunächst am Thema der Technik, greift aber schon bald über auf andere problematische Zukünfte, an die die Gegenwart anzupassen ist: Demografie, Wirtschaft, Migration oder Aussenpolitik.

Für das vereinzelte Individuum stehen ab den 1980er-Jahren deutlich andere Antworten bereit, wie es seine Zukunftsangst nun unter dem Namen Generalized anxiety disorder zu bewältigen hat. Es wirkt, als ob hier statt des Gebots einer Heuristik der Furcht der Imperativ einer Ignoranz der Angst sich Bahn bricht. Vielleicht deshalb setzt man beim Subjekt eher auf Therapien statt auf Texte. Wer unter Zukunftsangst leidet, dem wird fortan mit Kognitiver Verhaltenstherapie, Benzodiazepinen und/oder Antidepressiva geholfen. Doch wie gesagt: Alle diese mehr oder weniger praktischen Antworten werden erst spät auf die deutlich frühere Genese einer Zukunftsangst gefunden. Und diese beginnt spätestens in Kierkegaards verworrener Schrift Der Begriff Angst eine erkennbare Gestalt anzunehmen. 
Der zweite Grund, sich zumindest mit Blick auf die Entstehungsphase der Zukunftangst auf philosophische Texte zu konzentrieren, beruht auf der Fragilität des Gegenstandes. Die Ausdifferenzierung der Ängste in Sach-, Sozial- und Zeitphobien ist ein unwahrscheinlicher Prozess, der sich, wie bereits erwähnt, erst spät an Veränderungen gesellschaftlicher Strukturen dingfest machen lässt. Aus diesem Grund kommen Texte infrage, die immerhin dank ihres begrifflichen Differenzierungsvermögens es fertigbringen, die Ängste auszubuchstabieren. Das schliesst keineswegs aus, dass es bereits vor diesen Versuchen, die Angst auf den Begriff zu bringen, literarische Darstellungen, dramatische Verarbeitungen oder Verbildlichungen (vgl. Abb. 1) von Zukunftsangst gegeben haben mag. Nur: Als Hauptdarstellerin scheint diese darin nicht aufzutauchen. Erst die philosophischen Texte bieten ihr exklusiv eine Bühne.

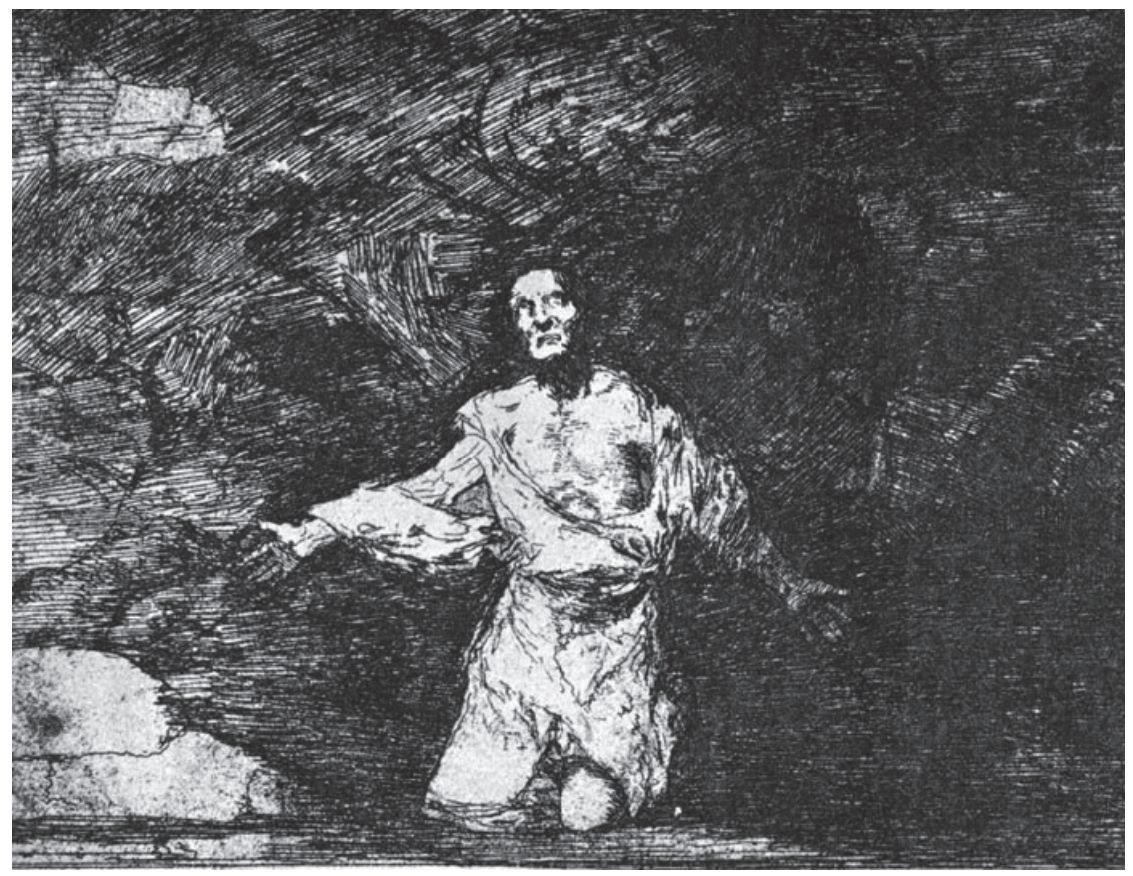

Abbildung 1: Francisco de Goya: «Traurige Vorahnung davon, was geschehen muss / Tristes presentimientos de lo que ha de acontecen», Los Desastres de la Guerra, Blatt 1, 1814-1815. Goyas Aquatinta wäre die perfekte Verbildlichung einer Zukunftsangst, wäre da nicht der störende Kontext. Denn die Angst bezieht sich hier nicht auf eine offene Zukunft und damit auf all das, was geschehen könnte, sondern auf das, was geschehen muss: auf die bevorstehenden Gräueltaten, die die Soldaten Napoleons an der aufständischen spanischen Bevölkerung verüben werden. 
Diese Bemerkungen implizieren keine philosophische Geschichtsschreibung, die die klügsten - und erst noch männlichen - Köpfe des 19. und 20. Jahrhunderts über die Angst so reden lässt, als ob es sich bei ihr um eine Konstante des animal rationale handelt, darauf wartend, mit den richtigen Worten und Begriffen endlich entdeckt zu werden. Die philosophischen Texte stehen vielmehr mit der Angst und ihren Veränderungen in einem seismografischen Verhältnis: Sie registrieren mal grössere oder kleinere Veränderungen, die sie zu deuten suchen. Wo jedoch das Epizentrum dieser Wellen liegt, entzieht sich ihnen mit grosser Wahrscheinlichkeit.

Die angestrebte Geschichtsschreibung weist viele Berührungspunkte mit dem Forschungsansatz der Historischen Anthropologie auf. Ihr Anliegen ist die Analyse von historischen Veränderungen des Menschen. Damit spricht sie sich einerseits gegen eine Anthropologie aus, die den Menschen auf invariante und überzeitliche Konstanten reduziert. Viel eher gilt ihr der Mensch im Sinne Nietzsches als «das nicht festgestellte Tier», das abhängig von seiner Zeit sich jeweils unterschiedlich präsentiert und konstituiert. Andererseits will eine solche Anthropologie den Menschen aber auch nicht gänzlich den historischen Umständen preisgeben, die dieses sonderbare Tier gleichsam von aussen fixieren und ihm keine 〈Substanz〉 jenseits des historischen Geschehens einräumen. Sowohl gegen eine zu essenzialistische als auch eine zu relativistische Anthropologie wird eine dialektisch anmutende Perspektive aufgeboten:

«Vielmehr wird das «Subjekt im wörtlichen Sinne als doppelt ambivalent begriffen: einerseits als das ZZugrundeliegende), ohne dessen Wollen und Handeln das Soziale und die Kultur unzugänglich bleiben, andererseits als das «Unterworfene», das sich in vorgegebene Strukturen einfügen muss.» (Tanner 2012, 4).

Die von der Historischen Anthropologie eingeforderte Ambivalenz bei der Historisierung des Menschen gilt tel quel für die hier bemühte Geschichte der Angst. Zum einen will sie die Angst als ein grundlegendes Gefühl, ja als ontologischen Gefühlsbestand verstanden wissen, der, um es mit Hobbes zu formulieren, mit dem Menschen auf die Welt gekommen ist. Es gibt Angst. Zum anderen aber möchte die Geschichte die Angst in ihrer Historizität sichtbar machen. Da die Angst an die Ressource von Sinn gekoppelt ist, entgeht sie auch nicht den historischen Veränderungen, die sich in neuen Diskursen und Semantiken, neuen Strukturen und Institutionen niederschlagen. Wie und als was sich die Angst, dieses nicht festgestellte Monster, de-monstriert, ist abhängig mitunter vom Schicksal ganzer Gesellschaften, an deren Geschichte die Angst wiederum fleissig mitschreibt. Die Angst ist geschichtlich. 
Angesichts dieses zweifachen Horizonts bietet es sich an, von einer historischen Ontologie der Angst zu sprechen.

\subsection{Erfindung und Entdeckung der Angst}

Dank dieser Analytik gelingt es, den vielfach interpretierten Angsttraktaten von Kierkegaard, Freud und Heidegger eine von der gewohnten Rezeption abweichende Leseart abzugewinnen. Mitnichten sollen die Texte als Dokumente gelesen werden, in denen ein Sinn schlummert, der mithilfe einer subtilen Hermeneutik erst zu erschliessen ist (vgl. Foucault 1981, 198). Nicht um Interpretation, sondern um Rekonstruktion soll es gehen. Doch von was? Die Texte sind Manuale, Bedienungsanleitungen oder Protokolle, mit denen sich teils gigantische Apparaturen und Versuchsanordnungen nachbauen lassen, in denen sich die Zeit- bzw. Zukunftsangst wie in einer Nebelkammer so ionisieren lässt, dass sie auch für das normale Auge sichtbar wird.

Anhand der Texte lassen sich Experimentalsysteme und Angstdetektoren nachbauen, die hinsichtlich ihres Untersuchungsgegenstandes aber eine genauso ambivalente Rolle spielen wie die Apparaturen der Natur- und Technikwissenschaften. Denn auch diese dienen der Erfindung und Entdeckung von Phänomenen gleichermassen. So hat beispielsweise bereits im 19. Jahrhundert die Elektrizitätslehre damit begonnen, die Erscheinung, die sie interessierte, systematisch mit ihren eigenen Instrumenten herzustellen: «An die Stelle der Übernahme von Elementen aus der Umwelt tritt das Phänomen, dass die Wissenschaft [...] alle Elemente, aus denen sie besteht, selbst produziert.» (Stichweh 1994, 58) Dank dieser erfindend-entdeckenden Forschungen und Apparaturen ist die Elektrizität kein Phänomen der Natur mehr, sondern zur Infrastruktur einer technisierten Welt avanciert.

Für die Angst gilt das Gleiche wie für die Elektrizität. Unterschiedslos sind sie beide Erzeugnis und Voraussetzung der jeweiligen Apparaturen, die zu ihrem Nachweis erbaut worden sind. Wenn die Angst und besonders die Zeitangst eine Geschichte hat, findet diese nicht nur ausserhalb, sondern auch innerhalb der Texte statt, die zu ihrer Entdeckung geschrieben worden sind. Die Texte sind teils filigran, teils wuchtig zusammengewerkelte Differenzialapparate, die eine nur wenig differenzierte Angst aufspüren, sie mit anderen Begriffen, Dingen und Psychen in Beziehung setzen und so die Ausdifferenzierung der Angst als Zeitangst vorantreiben. Wie ein Elementarteilchen beginnt auch die Zeitangst ihre Geschichte in Gestalt von Hypothesen und ersten Messungen. Ihre Existenz ist zunächst kaum mehr als ein theoretisches Postulat von Kierkegaard. Erst die Texte Freuds schälen sie als empirisch vorfindlichen Symptomkomplex aus der Neurasthenie einerseits, aus 
den sachlichen und sozialen Ängsten andererseits heraus. Und schliesslich ersinnt Heidegger in Sein und Zeit einen gigantischen Apparat, der Zeit und Angst auf einen Nenner bringt.

Eine historische Ontologie der Angst schlägt so nicht nur eine Brücke zwischen einer Ontologie und einer Genealogie der Angst, sondern auch zwischen einer Entdeckung und Erfindung der Angst.

\section{Die Ordnung der Angst}

In zeitdiagnostischen Dokumenten der Gegenwart nimmt die Angst inzwischen einen prominenten Platz ein. Die Angst, nicht normal zu sein, ist etwa für Jürgen Link (2006) ein entscheidender Motor dafür, dass Subjekte sich mithilfe von Infografiken und Illustrationen von Normalverteilungen jeweils flexibel in die Mitte der Gesellschaft einordnen. Diese Denormalisierungsangst befiehlt, uns nicht zu extravagant, aber auch nicht zu angepasst zu verhalten, uns nicht zu aggressiv, aber auch nicht zu passiv zu geben, nicht zu links, aber auch nicht zu rechts zu politisieren. Die Angst, etwas zu verpassen, wiederum ist für Hartmut Rosa der unbewegte Beweger unserer Bemühungen, in der begrenzten Zeit unseres Lebens möglichst viele Optionen zu realisieren, um am Ende ein Leben reich an Erfahrungen und ausgeschöpften Möglichkeiten vorweisen zu können. Diese Verpassensangst führt zu einer Beschleunigung unseres Lebenstempos bis an die Grenzen der Erschöpfung (Rosa 2013, 39ff.). Bei Ulrich Beck schliesslich gerät Angst gar zum Kriterium, anhand dessen sich die Klassengesellschaft von der Risikogesellschaft unterscheiden lässt:

«Die treibende Kraft in der Klassengesellschaft lässt sich in dem Satz fassen: Ich babe Hunger! Die Bewegung, die mit der Risikogesellschaft in Gang gesetzt wird, kommt demgegenüber in der Aussage zum Ausdruck: Ich habe Angst!» (Beck 1986, 66)

Der Begriff der Angst wird zur Diagnose unserer Kultur und Gesellschaft zwar grosszügig verwendet, erfährt aber selten je eine weiter gehende Analyse. Das gilt selbst für Heinz Budes Buch Gesellschaft der Angst (Bude 2014). Mit einem beeindruckenden Auflösungsvermögen für soziale Abhängigkeiten durchquert Bude die Gesellschaft und entdeckt dabei noch die subtilsten Ängste: Verlassensängste in der Partnerschaft, die Statusängste der Aufsteiger, die Ängste auf den unteren Etagen, die Angst, in einer «Winner takes it all»-Gesellschaft leer auszugehen usw. Wer vor der Lektüre des Buches noch keine Sozialphobien bei sich feststellen konnte, hat sie danach bestimmt. 


\subsection{Die Konjunktur der Angst}

Der Theoriemangel, mit dem in den Sozialwissenschaften Ängste diagnostiziert und vervielfältigt werden, findet sich in der psychiatrischen und psychologischen Literatur wieder. Die beiden Klassifikationssysteme DSM-IV und ICD-10 unterscheiden inzwischen folgende Angststörungen (hier DSM-IV):

$300.1 \quad$ Panikstörung ohne Agoraphobie

$300.21 \quad$ Panikstörung mit Agoraphobie

300.22 Agoraphobie ohne Panikstörung in der Vorgeschichte

300.29 Spezifische Phobie

Tierphobien: z. B. Angst vor Spinnen (Arachnophobie), Insekten, Hunden

Situative Phobien: Flugangst, Höhenangst, Tunnel, Aufzüge, Dunkelheit

Natur-Phobien: z. B. Donner, Wasser, Wald, Naturgewalten Anblick von Blut (Blutphobie), Spritzenangst (Trypanophobie), Verletzungen

$300.23 \quad$ Soziale Phobie

$300.3 \quad$ Zwangsstörungen

$300.81 \quad$ Posttraumatische Belastungsstörung

$308.3 \quad$ Akute Belastungsstörung

300.89 Generalisierte Angststörung

293.89 Angststörung bei körperlicher Erkrankung

Substanzinduzierte Angststörung

300.00 Angststörung, nicht näher bezeichnet

Selbst einzelne Herausgeber der Klassifikationssysteme merken inzwischen kritisch die Vervielfältigung der Angststörungen an - eine Amplifikation überdies, die sich in zunehmend komplexen und nicht mehr widerspruchsfreien Differenzialdiagnostiken niederschlägt. Diesbezüglich wird auch die «theoretizität des Systems angemerkt:

«Auf interpretative oder theoretisch-diagnostische Einteilungsaspekte der Klassifikation wurde verzichtet und eine «atheoretische> Klassifikation [...] psychischer Störungen angestrebt.» (Konermann/Zaudig 2003, 72)

Diese atheoretische, ja schier kopflose Vervielfältigung der Ängste erlaubt die Bildung verschiedener sozialwissenschaftlicher Hypothesen. Zunächst lässt sich die gesellschaftliche Zunahme von Angststörungen mithilfe einer Entstigmatisierung psychischer Störungen deuten: Immer mehr Menschen 
trauen sich, bei seelischem Leid den Psychologen oder Psychiater aufzusuchen. Im Jahr 2010 waren ganze 15 Prozent der Deutschen wegen krankhafter Angst beim Arzt. Ausserdem steht der sprunghafte Anstieg der Ängste Ende der 1980er-Jahren in engster Verbindung mit der Erarbeitung der neuen Klassifikationssysteme. Angststörungen wurden zuvor meist unvollständig unter «psychische Störungen» oder «psychiatrische Erkrankungen» subsummiert.

Bezieht man diese Faktoren in die Gleichung mit ein, bleibt immer noch unklar, in welchem Ausmass gesellschaftliche Veränderungen zur Ausbreitung von Angststörungen und der Sensibilität ihnen gegenüber beigetragen haben.

Eine Vermutung könnte lauten, die Herausbildung zunehmend aushandlungsbedürftiger Beziehungen in einer «entbetteten» Gesellschaft (Giddens) erhebe Gefühle sozialer Unsicherheit vermehrt auf das Niveau der Angst. Eine solche Hypothese wäre allerdings nur imstande, eine Antwort auf die Zunahme von sozialen Ängsten zu geben. Die grosse Prävalenz von Agoraphobien wiederum könnte unter dem Gesichtspunkt einer Vermassung der Gesellschaft interpretiert werden: Die Angst, die das Subjekt bei grossen Menschenansammlungen überfällt, wäre hier der Indikator. Eine weitere Hypothese könnte die zunehmende Bereitschaft, Ängste zu diagnostizieren und zu pathologisieren, in Rechnung stellen - eine Bereitschaft, die auf die immer grössere Bedeutung von Pharmakonzernen schliessen lässt. Die Leistungsgesellschaft wiederum liesse sich in einer vierten Hypothese aufbieten, um etwa die rapide Zunahme der generalisierten Angststörung beim «erschöpften Selbst» (Ehrenberg 2004) zu erklären.

Diese und weitere Hypothesen werfen die Frage auf, ob mit einer soziologisch gehaltvollen These die Vervielfältigung aller Ängste überhaupt in Blick genommen werden kann. Insofern die Ängste eine enorme Bandbreite aufweisen und bei weitem nicht alle sich als Sozialphobien zu erkennen geben, bleibt fraglich, wie diese Angstamplifizierung in nahezu allen Dimensionen zu deuten ist.

Womöglich lässt sich das Tableau der Ängste besser historisch als soziologisch durchdringen. Für die Geschichtswissenschaft mag sich deshalb die Frage nach einer Genealogie der Angst stellen. Welche Brüche und Zäsuren würden eine solche Geschichte der Angst durchziehen? Besonders die Publikation von Jean Delumeaus Angst im Abendland (1989 [Orig. 1983]) hat zu einer intensivierten Beschäftigung mit der Angst aus historischer Perspektive geführt. Allerdings stellt noch im Jahr 2006 ein Überblicksartikel die Frage, 
ob die Geschichte der Angst eine Geschichte eines fundamentalen Wandels oder die Geschichte einer psychosozialen Konstante ist (Stearns 2006, 482).

\subsection{Die Ausdifferenzierung der Angst}

Historisch und soziologisch zugleich lässt sich das gigantische Orchester der Angst zu Beginn des 21. Jahrhunderts mithilfe der zunächst wenig aussagekräftigen These einer Ausdifferenzierung deuten. Die Frage ist nur: mit welcher? Eine funktionale Differenzierung scheidet aus, da die Ängste quer zu den Funktionssystemen liegen: Es gibt - will man nicht sarkastisch sein keine Phobien, die typisch für Wirtschaft, Politik, Medien oder Religion sind. Dass Pfarrerinnen, Stars, Politikerinnen und Manager zwar Ängste, aber keine systemspezifischen Ängste kennen, das beweisen auch Psychotherapeutinnen und Psychiater, die solidarisch zu allen Berufsgruppen sind: Sie empfangen gerne jede und jeden als Kunden. Eine stratigrafische Differenzierung wiederum vermag in der Tat einige Ängste zu deuten, letztlich aber auch nur jene von Scheu und Scham, die Ängste also vor sozialer Degradierung. Die sparsamste Differenzierung ist die Differenzierung entlang der drei Sinndimensionen: sachlich, zeitlich, sozial.

Die Unterscheidung geht auf Niklas Luhmann zurück, der mit ihr Sinn, wie er im Bewusstsein oder in der Kommunikation zum Tragen kommt, in eine sachliche, eine soziale und eine zeitliche Dimension zerlegt hat (Luhmann 2000, 114-147). In der Sachdimension geht es um Gegenstände oder, gesellschaftlich betrachtet, um Themen, die in Kommunikationen abgearbeitet werden. Letztlich steuert diese Dimension, um was es im Bewusstsein oder in der Kommunikation gehen soll: um dies und nicht um jenes. Um die Burka und nicht um die Krawatte. In der Sozialdimension hingegen spielt die Zurechnung von Sinn auf sich selbst oder andere die entscheidende Rolle. Hier geht es vor allem auch um die Multiperspektivität bzw. -lateralität von Sinn: Wie unterscheidet sich Egos Erleben von Alters Erfahrung? Gerade übergriffige Eltern können diesbezüglich ein Lied davon singen, wie schwer es zu akzeptieren ist, dass der Nachwuchs eigene Vorstellungen vom Leben entwickelt, wo er doch noch Jahrzehnte vom Erfahrungsreichtum der Eltern profitieren könnte. In der Zeitdimension schliesslich wird Sinn auf ein Vorher und Nachher der Kommunikation bezogen. Dadurch wird es der Kommunikation oder dem Bewusstsein möglich, auf Künftiges oder Vergangenes zu- und zurückzugreifen. Gesellschaftlich wird die Zeitdimension genau dann zum Problem, wenn die Autoritäten der Vergangenheit auf die Verheissungen der Zukunft prallen, wenn Bücher also gegen Pläne antreten. 
Dies/jenes, Alter/Ego, vorher/nachher - das sind die Leitdifferenzen, die den Sinn in eine sachliche, soziale und zeitliche Dimension zergliedern.

Trotz dieser theoretischen Anleihe weicht die vorliegende Angstunterscheidungsthese von Luhmanns Sinndifferenzen erheblich ab. Denn Luhmann erwartet von seinen Sinndimensionen keine historisch und gesellschaftlich relevante Ausdifferenzierung. Für Luhmann gibt es keine gesonderten Sach-, Sozial- und Zeitstrukturen, höchstens im metaphorischen Sinne. Luhmanns Gesellschaft differenziert sich also nicht entlang der Sinndimensionen aus. Dafür sind andere Prinzipien wie jene der funktionalen Differenzierung verantwortlich, die die Gesellschaft in Funktionssysteme wie Wissenschaft, Wirtschaft, Politik, Medien oder Recht zergliedern. Gleichsam quer zu dieser gesellschaftlichen Ausdifferenzierung behauptet der vorliegende Beitrag in der Tat aber eine zunehmende Spezialisierung und Konkretisierung der Angst im Hinblick auf ihre Gegenstände (sachlich), auf ihre Kontexte (sozial) sowie auf ihre Zeiten (zeitlich).

\section{Ausdifferenzierung der Angst (sachlich, sozial, zeitlich)}

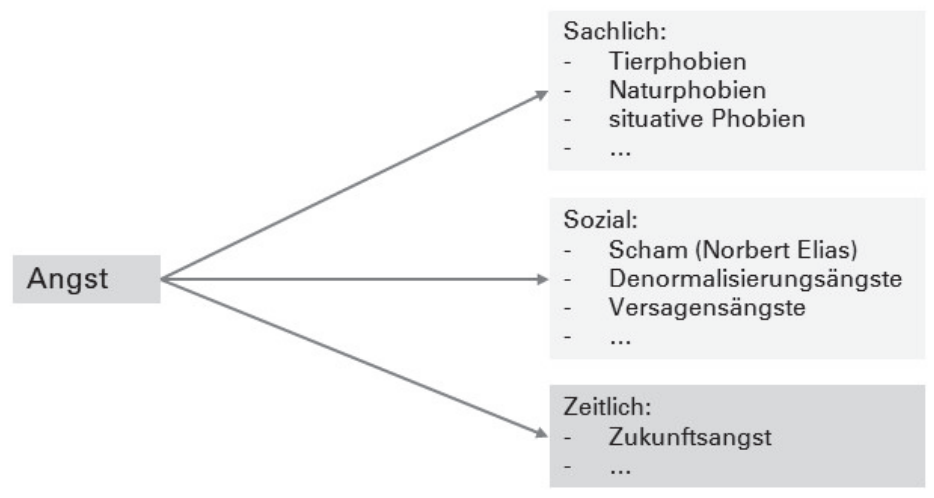

Abbildung 2: Die These

Die Behauptung einer Ausdifferenzierung der Angst in der sachlichen, zeitlichen und sozialen Sinndimension ist, wirft man einen Blick auf die Gesellschaftsstrukturen, die dies begünstigen, auf den ersten Blick wenig folgenreich. Selbst die schlimmsten Ängste bringen kein entsprechendes Funktionssystem hervor - abgesehen vielleicht von der Religion. Die Spezialisierung der Ängste muss eher als Antwort auf eine Komplexitätszunahme der gesamten 
Gesellschaft gedeutet werden. Diese makrosoziologische Harmlosigkeit der Angstdifferenzierung bedeutet aber nicht, dass die im Sinn gesonderten Ängste keine Strukturanpassungen auf der Mesoskala hervorbringen. Im Gegenteil: Die Anfänge der Sozialpolitik lassen sich möglicherweise umstandslos als Antwort auf die drastische Zunahme von sozialen Ängsten begreifen. Und die Chronopolitiken der jüngsten Zeit sind Reaktionen auf eine zeitlich ausdifferenzierte Angst: die Zukunftsangst.

Auf jeden Fall bestätigen sowohl die diversen Ängste in zeitdiagnostischen Dokumenten als auch die Vielzahl von Ängsten in den internationalen Klassifikationssystemen den Verdacht einer Ausdifferenzierung der Angst zunächst vor allem in der sachlichen und sozialen Dimension. Einerseits richten sich die Ängste auf immer mehr Gefahren, die den Menschen an Leib und Leben bedrohen - wie im Fall der Tier-, Blut- oder situativen Phobie (u. a. Flugangst). Andererseits rücken Ängste wie die Agoraphobie oder die Soziale Phobie genuin soziale Gefahren ins Zentrum. Hier wird nicht eine Beeinträchtigung des biologischen, sondern des Lebens in der Gemeinschaft und Gesellschaft befürchtet - aufgrund eines selbst verschuldeten Verlusts der Anerkennung durch andere. Auch Links Denormalisierungsangst ist keine Angst vor gefährlichen Dingen, sondern eine Angst vor einem bzw. einer imaginären Anderen, der oder die mit Entzug gesellschaftlicher Anerkennung droht. Hier entspringt die Gefahr nicht einer Sache oder einem Lebewesen, sondern der sozialen Differenz von Individuum und Gesellschaft.

Angesichts der sachlichen und sozialen Ausdifferenzierung der Angst stellt sich die Frage, wie es um die zeitliche Dimension bestellt ist. Lässt sich auch hier eine Ausbreitung und Spezialisierung registrieren? Eine Antwort darauf gibt zunächst zu bedenken, dass fast alle Ängste temporale Phänomene sind. Schliesslich richten sie sich auf künftige Ereignisse, die so, wie befürchtet, noch nicht eingetreten sind und die weit seltener als antizipiert eintreten werden. Die meisten Ängste sind gleichsam in die Differenz von Zukunft und Gegenwart aufgespannt: Sie finden im Hier und Jetzt statt, zielen aber auf künftige Ereignisse und Situationen. Stellt man dies in Rechnung, lässt sich präziser fragen: Gibt es neben einer Ausdifferenzierung von Sachund Sozialängsten auch eine der Chronophobie?

Tatsächlich soll dies hier behauptet werden: Nämlich, dass Zeit selbst zum Objekt der Angst avanciert ist. Neben Rosas Verpassensangst kommt die steile Karriere des Begriffs der Zukunftsangst seit den 1970er-Jahren in deutschsprachigen Texten als historisch später Beleg infrage (vgl. Abb. 3). 


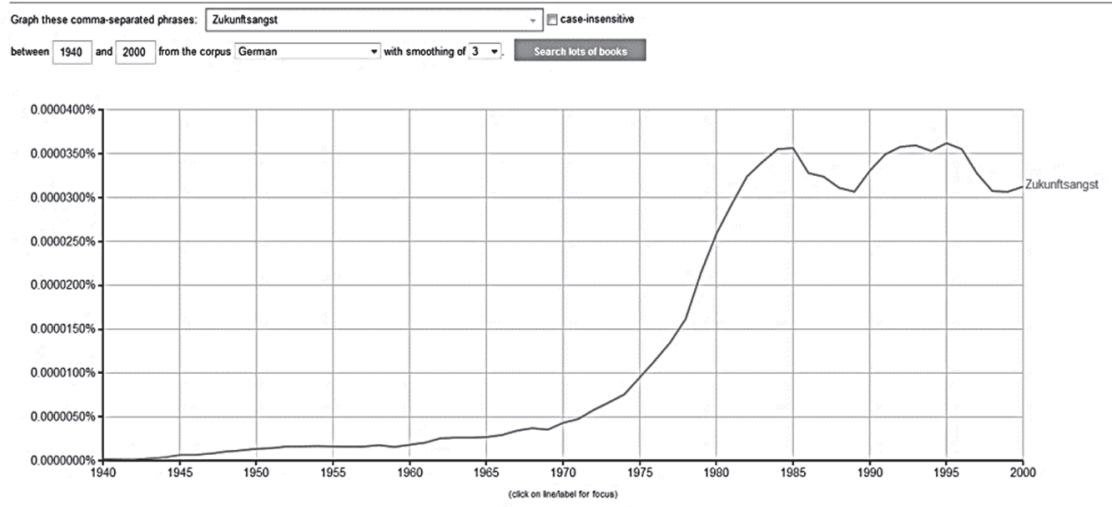

Abbildung 3: «Zukunftsangst» im deutschsprachigen Korpus von Google Books, 1940-2000.

Doch auch im Falle der Generalisierten Angststörung, deren Vorläuferin Freuds neurotische Angst ist und die seit den 1980er-Jahren sich in Büchern immer häufiger findet (vgl. Abb. 4), spielt die Zukunft eine wesentliche Rolle. So hält das Lehrbuch für Klinische Psychologie unter den allgemeinen Merkmalen der Krankheit fest:

«Das allgemeine Erscheinungsbild von Menschen mit einer generalisierten Angststörung beinhaltet eine relativ konstante, in die Zukunft gerichtete Stimmungslage von ängstlicher Erwartung, chronischer Anspannung, Sorge und diffusem Unwohlsein. Die Betroffenen scheinen ständig auf das Auftauchen negativer Ereignisse vorbereitet zu sein und haben das starke Gefühl, die Besorgnis nicht kontrollieren zu können [...].» (Butcher u. a. 2009, 254)

Beide Ängste, sowohl die kollektive Zukunftsangst als auch die individuell therapiebedürftige Generalisierte Angststörung, plausibilisieren die These einer allmählichen Ausdifferenzierung der Angst: nicht nur in der sachlichen und sozialen, sondern eben auch in der zeitlichen Sinndimension.

Und diese Herausbildung einer spezifischen Zeitangst gilt es, im Folgenden mithilfe einer historischen Ontologie der Zukunftsangst nachzuzeichnen. 

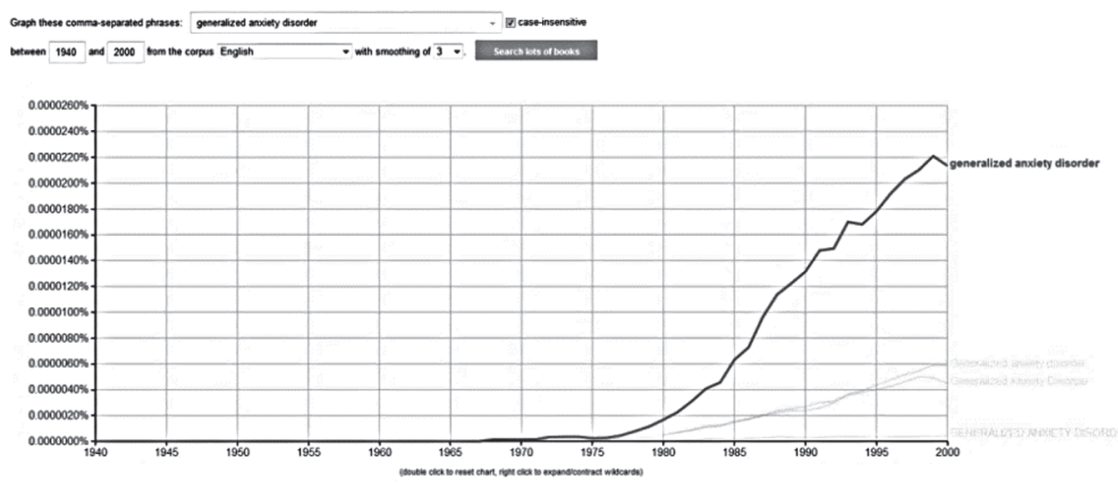

Abbildung 4: «Generalized anxiety disorder» im englischsprachigen Korpus von Google Books, 1940-2000.

\section{Interludium: Die Ausdifferenzierung der Angst zur Scham}

Wie kristallisiert sich aus einer dumpfen eine sensible Angst heraus? Wie bittet die Gesellschaft und ihre Geschichte um Einlass ins Gefühlsleben eines einzelnen Menschen? Glaubt man Norbert Elias, hat sich gut zweihundert Jahre vor der Zukunftsangst die Scham als soziale Angst einen Platz im emotionalen Haushalt gesichert. Die Geschichte ihrer Herausbildung dient als Schablone, um die Zukunftsangst ebenso erzählbar zu machen.

Scham ist ein Gefühl, das wir nur zu gut kennen - wir kennen es so gut, dass wir alles darum geben, es zu vermeiden. Die Angst davor, uns vor anderen lächerlich zu machen, vor ihnen nackt und wehrlos dazustehen, ja vor ihnen den sozialen Tod zu erleiden, bestimmt nicht nur unser tägliches Handeln, sondern beschleicht uns in der Nacht noch, wenn wir uns im Traum infolge einer Dummheit oder Hochstapelei der Lächerlichkeit preisgeben.

In seinem zweibändigen Werk Über den Prozess der Zivilisation hat Norbert Elias der Scham und ihrer Geschichte ein Denkmal errichtet. Die gute Nachricht lautet: Selbst unsere Albträume, aus denen wir schweissgebadet aufwachen, haben eine Geschichte. Die schlechte Nachricht: Sie sind Ergebnis und Produkt einer Transformation der Gesellschaft, der wir nicht entrinnen können. Mögen unsere Vorfahren ob des Anblicks eines Mammuts, das seine Vorderfüsse bedrohlich anhebt, aus dem Schlaf hochgefahren sein, ist es unser Schicksal, bei einem Vortrag vor Gästen von der Angst eingeholt zu werden, der Hosenladen stehe offen oder die Schminke sei zerlaufen. 
Und genau darin besteht die Originalität von Elias' Rekonstruktion unserer Zivilisation: Die Veränderung der Gesellschaft geht einher mit einer Veränderung der individuellen Persönlichkeit und mit ihr: ihrer Ängste. Und in dieser Geschichte nimmt die Scham als soziale Angst eine besondere Rolle ein. Denn sie ist Indikator und Seismograf dieser sowohl gesellschaftlichen wie individuellen Transformationsprozesse.

Elias untersucht diese Veränderungen im Verhalten insbesondere der höfischen Oberschichten vom Ausgang des Mittelalters bis ins 18. Jahrhundert. Gesellschaftlich ereignet sich in dieser Zeit eine Entwicklung, die Elias mit Zivilisation anspricht, die er aber als Prozess und nicht als Zustand konzipiert. Diese civilisation bzw. Zivilisierung geschieht in erster Linie durch die Herausbildung des Staates, der immer mehr Funktionen zentralisiert. Für die Entwicklung der Angst massgeblich ist dabei die Monopolisierung der Gewalt, die zur Entwaffnung des Kriegs- bzw. Ritteradels führt. Diese Verstaatlichung macht Gewalt rational erwartbar und entzieht sie der ungeregelten und willkürlichen Anwendung, wie sie im Mittelalter üblich war. Erst mit diesem Schritt eröffnet sich für die Menschen jene Sicherheit, die eine Lang- und Weitsicht erst ermöglicht.

«Wenn sich ein Gewaltmonopol bildet, entstehen befriedete Räume, gesellschaftliche Felder, die von Gewalttaten normalerweise frei sind. [...] Hier ist der Einzelne vor dem plötzlichen Überfall, vor dem schockartigen Einbruch der körperlichen Gewalt in sein Leben weitgehend geschützt; aber er ist zugleich selbst gezwungen, den eigenen Leidenschaftsausbruch, die Wallung, die ihn zum körperlichen Angriff eines Anderen treibt, zurückzudrängen.» (Elias 1997b, 331f.)

Anhand des entwaffneten Adels zeichnet Elias die Veränderungen nach, die aus dieser Soziogenese im Sinne eines Staatenbildungsprozesses resultieren. Und diese greifen so tief in das Seelenleben der Menschen ein, dass Elias gar von einer Psychogenese spricht. Im Zuge dieses Umbaus von Individuum und Gesellschaft kommt schier alles, was an körperliche Auseinandersetzung auch nur entfernt erinnert, unter eine neue Herrschaft zu stehen: die der eigenen Lust- und Affektkontrolle. Fremdzwänge verwandeln sich in Selbstzwänge (Elias 1997b, 324).

Der gewaltsame Konflikt wird gänzlich von aussen nach innen verlagert: Er darf nicht mehr ausgefochten, sondern muss bei der stillen Lektüre von Ritterromanen nachempfunden werden. Er darf nicht mehr zwischen Menschen entschieden, sondern muss im Individuum ausgetragen werden. Letztlich darf er nicht mehr vom Es angestachelt, sondern muss vom Über-Ich ständig im Zaum gehalten werden (Elias 1997b, 341) 
Diese Internalisierung des Konflikts lässt auch den unbewaffneten Körper nicht unberührt. Beinahe jede Form von Körperlichkeit gerät bei der Zivilisierung des Adels unter Verdacht. Die Manierenbücher der Renaissance empfehlen, das Problem des aufdringlichen und ausscheidenden Körpers einerseits durch die Verbannung aus dem öffentlichen Raum, andererseits durch eine erlesene Etikette zu lösen. Urinieren und Kopulieren werden in neue Räume oder aber ins dunkle Schlafgemach abgedrängt. Schnäuzen und Spucken werden weitgehend invisibilisiert und das Speisen zu Tisch peinlich genau reguliert.

Bemerkenswerterweise richten sich die Erwartungen an eine solche Höflichkeit zunächst an die jeweils Untergebenen. Sie müssen durch ihre Unterwerfung unter dieses Zeremoniell ihre Friedfertigkeit und damit die Akzeptanz der monopolisierten Gewalt demonstrieren. In Frankreich empfangen die Könige im 17. Jahrhundert die höflich affektkontrollierten Untergebenen bei Gelegenheiten, die heute, in einer egalisierten Gesellschaft, als peinlich gelten müssen: beim Umziehen, beim Zubettgehen, beim Aufstehen (Elias 1997a, 279). Höflichkeit muss in erster Linie nach oben, nicht nach unten gezeigt werden.

Diese Zivilisierung ist für die Ausdifferenzierung der Scham aus der Angst entscheidend. Die Angst um sein Leben schwindet in dem Masse, wie die Gewalt rationalisiert und zum kalkulierbaren Risiko gemacht wird. Ihren Platz übernimmt eine genuin soziale Angst, die den Aufbau der höfischen Gesellschaft en détail abbildet. Die Scham betritt als Angst vor sozialer Degradierung (Elias 1997b, 408) die Hallen der Seele. Und sie ist zunächst hierarchisch organisiert: Empfunden wird sie nicht nach unten, sondern nach oben. Sie dringt überall dort ein, wo die Höflichkeit durch eine kleine Unachtsamkeit oder minimale Unkenntnis der Etikette Schaden nehmen und deshalb als Respektlosigkeit ausgelegt werden könnte: beim Speisen, bei der Notdurft, beim Schnäuzen und beim Sprechen.

Da das spätere Bürgertum das höfische Verhalten übernehmen wird, diffundiert mit ihm auch die Scham in die Gesellschaft und wird über Erziehung vermittelt, von Generation zu Generation übergeben. Allerdings egalisiert sie sich nun, da die Abhängigkeiten zwischen den Menschen dank Arbeitsteilung zunehmen: Der Herr ist nun wahrlich auf den Knecht in Hegels Sinne angewiesen und entwickelt deshalb gegenüber letzterem Schamgefühle. Die Scham zielt nun in alle Richtungen.

Trotzdem wird sie weiterhin noch als Angst vor sozialer Degradierung empfunden. Sie bleibt als Gefühl der Unterlegenheit gegenüber anderen erhalten - eine Unterlegenheit, die nicht körperlich ist und deshalb auch nicht 
mit einem Angriff pariert oder durch Flucht annulliert werden kann. Die Wehrlosigkeit der Scham erklärt Elias mithilfe des im Zivilisationsprozess herangebildeten Über-Ichs. Die Überlegenheit der anderen ist somit nicht diesen zuzuschreiben, sondern den in der Erziehung angezüchteten Selbstzwängen, die das Ich gegenüber seinem höfisch aristokratischen Über-Ich unterlegen machen.

«Beim Erwachsenen aber kommt diese Wehrlosigkeit daher, dass die Menschen, deren Überlegenheitsgesten man fürchtet, sich in Einklang mit dem eigenen Über-Ich des Wehrlosen und Geängstigten befinden, mit der Selbstzwangsapparatur, die in dem Individuum durch Andere, von denen es abhängig war, und die ihm gegenüber daher ein gewisses Mass von Macht und Überlegenheit hatten, herangezüchtet worden ist.» (Elias 1997b, 408)

Hans Peter Duerr hat in seinem fünfbändigen Werk Der Mythos vom Zivilisationsprozess (1988ff.) Elias' These einer Verschränkung von Sozio- und Psychogenese einer monumentalen Kritik unterworfen. Darin zielen wichtige Monita gerade auf Elias' These einer Ausdifferenzierung der Scham im Gefolge einer fortschreitenden Zivilisierung. Duerr widmet u. a. seinen ersten Band Nacktheit und Scham dem Nachweis von Scham auch in Kulturen, die von einem vergleichbaren Prozess nicht erfasst worden sind und Elias zufolge als unzivilisiert gelten müssten. Gerade bei angeblich primitiven Völkern sieht Duerr die Schamschwelle noch weiter als am Hofe entwickelt, da diesen Face-to-face-Gemeinschaften keine Räume zur Verfügung stehen, die eine Grenze zwischen öffentlich und privat schaffen. Der Unterschied zwischen beiden Sphären werde, so Duerr, mitunter durch eine hohe Disziplinierung des Blicks etabliert, der schambewusst durch andere hindurchsieht oder nur spezifische Körperteile erfasst, um ihnen so ihre Privatheit zu gewährleisten.

Letztlich sei die Scham ein ubiquitäres Phänomen, das sich nicht einem Zivilisationsschub verdanke. Duerr spitzt seine Kritik zu einer theoretischen Skizze zu, in der die Scham - gleichsam ethnologisch assistiert - anthropologisiert wird. Die Scham ist, wie das Inzesttabu von Lévi-Strauss, kein Effekt von Gesellschaften, sondern deren Voraussetzung, da sie die Sexualität so zügle, dass sie sozialkonform wird.

Sieht man von der Anthropologisierung der Scham ab, ist Duerrs Kritik an Elias Zivilisationstheorie berechtigt - vor allem dort, wo Duerrs und Elias' Verständnis von Scham sich überschneiden. Das gilt insbesondere für die Regelung der Sexualität und die Organisation des Unterschieds zwischen einer privaten und einer öffentlichen Körperlichkeit. Elias verleiht seiner 
Scham aber eine Bedeutung, die sie in die Nähe von Versagensängsten bringt - Ängsten also, einer hierarchischen Ordnung nicht gerecht werden zu können. Scham bleibt nicht auf die Angst beschränkt, buchstäblich entblösst zu werden, sondern erweitert sich zur Angst, auch unabhängig von der Körperlichkeit entblösst zu werden - entblösst als jemand, der dem von ihm erwarteten Habitus nicht gerecht wird.

Duerrs Kritik an Elias' Zivilisationsthese ist berechtigt, wenn sie zu bedenken gibt, dass Scham als Gewalt- und Sexualitätsregulativ eben nicht nur in «zivilisierten〉 Gesellschaften vorzufinden ist. Sie zielt aber an Elias' Einsicht vorbei, wonach die Scham in der Lage ist, Fremdzwänge so in Eigenzwänge zu übersetzen, dass sie die Gesellschaftsstrukturen detailliert in einer feingliedrigen Ökonomie der Angst nachbildet. Dass diese Scham ein Resultat stratigrafischer Differenzierung am Hofe des 16. bis 18. Jahrhunderts ist, ist nicht unwahrscheinlich.

Doch nicht nur die Ausdifferenzierung jener Scham aus der Angst vor Gewalt verdient vor dem Hintergrund einer allgemeinen Angstdifferenzierungsthese Beachtung. Es ist überdies Elias' Vorschlag einer «historischen Psychologie» (Elias 1997b, 398), die in verblüffender Ähnlichkeit das Ansinnen einer historischen Anthropologie oder Ontologie vorwegnimmt: Die Psyche steht mit gesellschaftlichen Veränderungen in einem derart innigen Verhältnis, dass diese sich bis in die Triebstruktur des Individuums niederschlagen. Zugleich wirken diese Psychen und Triebe mit ihren hoch entwickelten und ausgeklügelten Wahrnehmungen so auf die Gesellschaft und Geschichte zurück, dass sie unmöglich mehr als Überbau oder Ideologie abgetan werden können (ebd.).

\section{Eine Geschichte der Zukunftsangst}

Der Vergleich mit Elias' Sozialphobie macht jetzt schon auf einen markanten Unterschied aufmerksam: Die Zukunftsangst kommt deutlich später zur Welt. Sie entwickelt sich erst nach der Entdeckung der Zukunft (Hölscher 1999) und damit nach der Verlängerung der Zukunft in einen endlosen Zeitraum. Die Herauslösung der Chronophobie aus dem Orchester der übrigen Ängste ist überdies im Kontext der Formierung des demokratischen Zeitalters zu sehen. Nicht ganz zufällig taucht die fragliche Angst wahrscheinlich erstmals in Tocquevilles Demokratie in Amerika (1835/1840) auf. Darin mokiert sich der Autor einerseits über die Angst, die den in der Demokratie vereinsamten Menschen aufgrund seiner «unbegrenzten Unabhängigkeit» befällt und ihn 
mit «Angst vor sich selbst» erfüllt. Andererseits spricht sich Tocqueville emphatisch für eine Zukunftsangst aus:

«Geben wir uns also jener heilsamen Furcht vor der Zukunft hin, die uns wachen und kämpfen heisst, und nicht jener weichlichen und untätigen Angst, die die Herzen bedrückt und sie zermürbt.» (Tocqueville 1976 [1840], S. 826).

Unabhängig davon, ob hier untätige oder echte Zukunftsängste im Spiel sind, der Kontrast zu den Ängsten, die noch Hobbes' oder Montesquieus Zeitalter beherrschten, könnte grösser nicht sein: Lebten Hobbes' Menschen noch in «ständiger Furcht und der drohenden Gefahr eines gewaltsamen Todes», sind die Bürger in Tocquevilles Diagnose von einer diffusen Angst und Unruhe umgeben, die kein Objekt in Gestalt eines Naturzustandes oder eines absolutistischen Staates mehr kennen. Es kündigt sich hier die Differenzierung von Angst und Furcht an.

\subsection{Station I: Kierkegaard}

Kurz nach Tocqueville taucht die Chronophobie in Sören Kierkegaards Traktat Der Begriff Angst (Kierkegaard 1992 [1844]) auf. Hier löst sie sich gänzlich aus ihrer Liaison mit den Sozialphobien, die bei Tocqueville noch in Gestalt von Statusängsten den demokratischen Bürger heimsuchen. Freilich führt Kierkegaard die von Tocqueville diagnostizierte Verbindung von Freiheit und Angst weiter. Mehr noch: Der dänische Philosoph radikalisiert die Beziehung dahingehend, dass Freibeit und Angst zu Synonymen werden. Oder anders ausgedrückt: Gäbe es ein Gefühl für die Freiheit, es wäre Angst.

Die fragliche Schrift ist nur eine von vielen, die in Kierkegaards merkwürdig explosiver Schaffensphase zwischen 1843 und 1846 erschienen sind. Sieht man von den religiös motivierten Christlichen und Erbaulichen Reden ab, teilt die Angstschrift mit allen philosophischen Werken eine weitere Merkwürdigkeit. Kierkegaard veröffentlicht sie nicht unter seinem eigenen $\mathrm{Na}$ men, sondern unter verschiedenen Pseudonymen: Für sein erstes Hauptwerk Entweder - Oder erfindet er Victor Eremita, für die Philosophischen Brocken Johannes Climacus und für Der Begriff Angst Vigilius Haufniensis, was so viel bedeutet wie Nachtwächter Kopenhagens.

Die Pseudonymisierung dient Kierkegaard nicht etwa zu einer politisch bedingten Verschleierung der Autorschaft. Dagegen spricht allein schon die Personalisierung der Schriften mithilfe von biografischen Notizen, mit denen Kierkegaard für die Bewohner Kopenhagens leicht erkennbar bleibt. Die Decknamen wollen vielmehr eine ironisch kognitive Distanz zwischen Autor und Inhalt schaffen, sodass der Verfasser Kierkegaard zum ersten Leser und 
Kritiker seiner eigenen Schriften avancieren darf. Ein ungebrochenes Verhältnis findet sich lediglich in den religiösen Texten: Hier ist es Kierkegaard, der in seinem eigenen Namen zu seinen Leserinnen und Lesern predigt. Diese Unmittelbarkeit erlaubt sich Kierkegaard aber nur im Wissen um die philosophischen Texte, die mit ihren Zweifeln an der Autorschaft die Aufrichtigkeit der wohlgemerkt fiktiven Predigten auch hier ironisch brechen. Kierkegaard bleibt selbst hier noch dem Paradox eines Autors treu, der zwar viele Schriften erzeugt, aber keine einzige autorisiert hat. The philosopher who wasn't there.

Es ist bei weitem nicht nur das Pseudonym, das eine Annäherung an den Begriff Angst erschwert. Denkwürdig präsentiert sich schon der Untertitel des Traktats: Eine einfache psychologisch-hinweisende Überlegung in bezug auf das dogmatische Problem der Erbsünde. Doch auch die weitere Lektüre konfrontiert selbst eine philosophisch geschulte Leserschaft mit Zumutungen en masse, die schon bald die Frage aufwerfen: Geht es dieser Schrift wirklich um die Angst, dieses unheimliche Gefühl, das einen wie aus dem Nichts überkommt? Hat der Begriff, den sich der Autor (wer immer es sein mag) von der Angst macht, überhaupt etwas mit der Erfahrung von Angst zu tun? Schreibt hier ein Philosoph nicht gänzlich an den Ängsten seiner Leserinnen und Leser vorbei?

Die These muss hier lauten: Kierkegaard erschreibt und beschreibt gleichermassen eine Grundbefindlichkeit, für die es in der ersten Hälfte des 19. Jahrhunderts noch kaum eine seelische Entsprechung und emotionale Tradition gibt. Was der dänische Philosoph mit seinem Begriff der Angst schreibend erahnt, ist eine delikate Mischung von Erfindung und Entdeckung zugleich.

\subsubsection{Die Erfindung der Angst}

Erfunden ist die Angst, da sie - zumindest zum Zeitpunkt der Veröffentlichung - mit keinem bekannten Gefühl und keiner kultivierten Erfahrung übereinzustimmen scheint. Die Entwicklung der Angst hat, modernisierungstheoretisch formuliert, in ihren Menschenwirten noch nicht den Differenzierungsgrad erreicht, den Kierkegaard behauptet. Was er mit seinem Begriff der Angst meint, hat im oikos der Gefühle noch keinen festen Standort. Zwar möchte sich die Angst phänomenologisch «gefühlt mit der Furcht an einen Platz setzen, nur: sie wird von da schnell vertrieben. Denn mit einer folgenreichen Unterscheidung fährt Kierkegaard zwischen die beiden. Die Furcht ist intentional, die Angst nicht. Die Furcht ist stets eine Furcht vor etwas seien dies Tiere, Menschenmassen, grosse oder kleine Räume. Die Angst hingegen ist ungerichtet. Das kommende 20. Jahrhundert wird diese Unterscheidung in Stein meisseln und so zur kaum reversiblen Differenzierung zwischen 
den sachlichen Furchten und Phobien auf der einen, der zeitlichen Angst auf der anderen Seite beitragen.

«Man findet den Begriff der Angst kaum jemals in der Psychologie behandelt, ich muss deshalb darauf aufmerksam machen, dass er gänzlich verschieden ist von Furcht und ähnlichen Begriffen, die sich auf etwas Bestimmtes beziehen [...]» (50)

Wie sehr Kierkegaards Angst ein erfundenes und ersonnenes Gefühl ist, zeigt sich mitunter an den Spitzfindigkeiten und Schwierigkeiten, die die Übersetzung von Begrebet Angest in andere Sprachen begleitet haben. Die erste englische Ausgabe, 1944 übersetzt von Walter Lowrie, trägt noch den Titel The Concept of Dread. Daraus wird erst später The Concept of Anxiety. Die kanonische Übersetzung fürs Italienische ist angoscia, fürs Französische angoisse. Sie alle rücken die Angst etymologisch in die Verwandtschaft zum indogermanischen anghu für «beengend» und, vorher noch, zum lateinischen ango für «würgen, erdrosseln, zuschnüren» sowie zum griechischen ő $\gamma \chi \omega$ mit ähnlicher Bedeutung. Damit distanzieren sich diese Übertragungen von semantisch näherliegenden Etymologien wie dem griechischen $\varphi$ óßos, der lateinischen timor oder dem peri(culum), das wiederum im Englischen zu fear sich wandeln wird. Obgleich also für die emotionale Qualität der Angst angemessene Bezeichnungen bereitstünden, suchen die Übersetzungen die Nähe zu den eher gesucht und artifiziell anmutenden Semantiken von «Enge» und «Beklemmung» auf. Das ist umso erstaunlicher, als eine der wenigen psychologischen Gefühlsbeschreibungen der Angst eine solche Einengung vermissen lässt. Nicht Enge, sondern Weite und Höhe sind die Trigger der Kierkegaard'schen Angst:

«Man kann die Angst mit einem Schwindel vergleichen. Wer in eine gähnende Tiefe hinunterschauen muss, dem wird schwindlig. Doch was ist die Ursache dafür? Es ist in gleicher Weise sein Auge wie der Abgrund - denn was wäre, wenn er nicht hinuntergestarrt hätte? Demgemäss ist die Angst jener Schwindel der Freiheit $[\ldots] »(72$; eigene Hervorhebung)

Kierkegaards Schrift Der Begriff Angst ist, um es mit Niklas Luhmann zu sagen, eine höchst unwahrscheinliche Kommunikation, deren Anschlussfähigkeit erst im 20. Jahrhundert zustande kommt. Sie erfindet ein Gefühl oder eine Befindlichkeit, für die es wenn überhaupt, vorerst nur vage, eine Passung in den Emotionskulturen und Gefühlssemantiken der damaligen Zeit gibt. 


\subsubsection{Die Entdeckung der Angst}

Und doch wird diese Angst von Kierkegaard nicht nur erfunden, sondern entdeck.t zugleich. Es ist müssig, darüber zu spekulieren, ob der Däne, der in Sorge um seine geistige Gesundheit die Verlobung mit der über alles geliebten Regine Olsen löst, aufgrund seiner Schwermut ein besonderes Sensorium für die eigentümliche Angst ausgebildet hat. Interessanter ist die Frage, mit welcher Apparatur, welchem Instrumentarium oder Detektor es Kierkegaard gelingt, Spuren in der Nebelkammer der Gefühle für seine postulierte und hypothetische Angst zu finden. Die Idee zu seiner Angst mag Kierkegaard durchaus von seinen Depressionen zugespielt worden sein. Doch die Prüfung ihrer Existenz vor dem Tribunal der Erfahrung obliegt nicht der Schwermut, sondern einer aufwendigen Versuchsanordnung, die den Vergleich mit den Detektoren in Teilchenbeschleunigern nicht zu scheuen braucht.

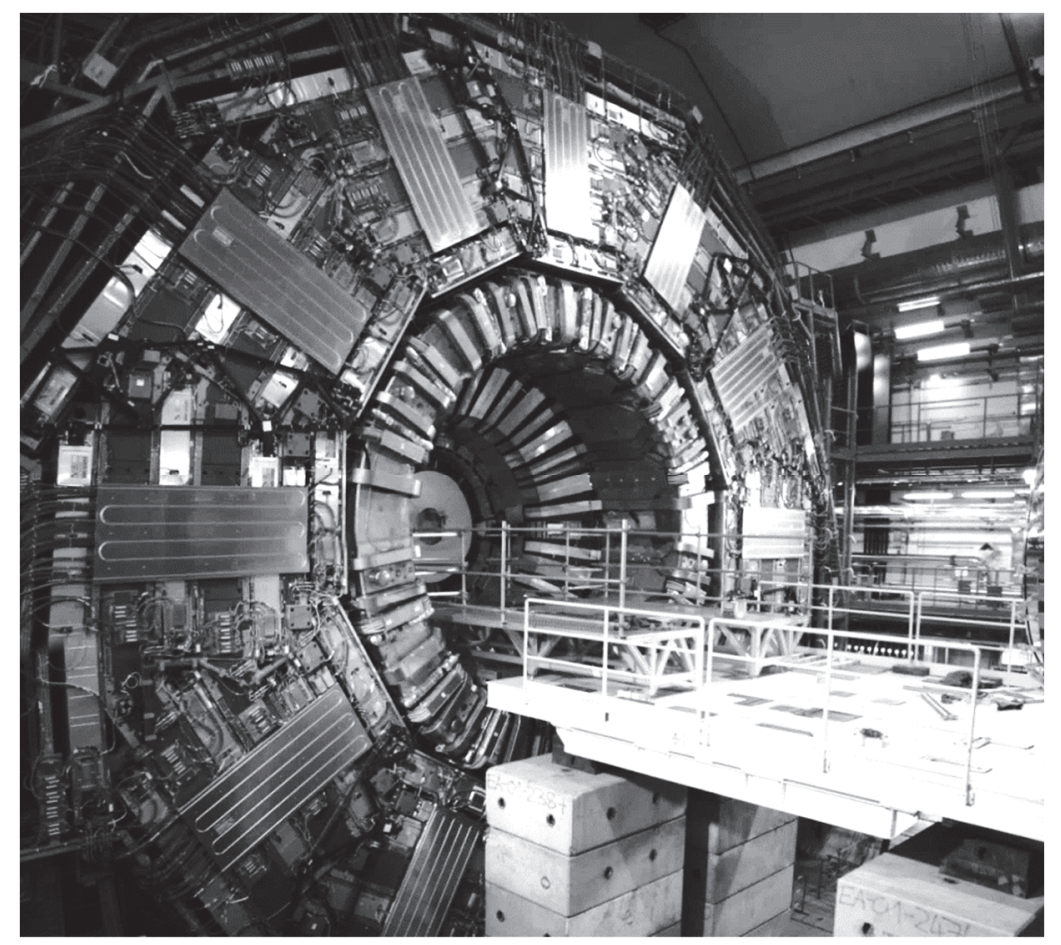

Abbildung 5: Einer der Detektoren am Large Hadron Collider am CERN. Quelle: Wikipedia.

Genauso wie am Large Hadron Collider in Genf postulierte Teilchen mithilfe einer diffizilen und zugleich brachialen A nordnung nachgewiesen werden sollen, 
zielt Kierkegaard mit seiner zumutungsreichen Schrift auf die Entdeckung eines emotions, das jetzt noch klein und unauffällig, schon bald die Last der Seelenunruhe des 20. Jahrhunderts zu schultern hat.

Die Entdeckung der Angst wird in erster Linie mithilfe einer neuen Interpretation der Ursünde vorangetrieben. Die Angst wird also nicht im Diesseits des 19. Jahrhunderts gepackt, sondern auf die ersten Gehversuche der Menschheit in einer mythischen Vorzeit zurückgeführt. Kierkegaard ersinnt dazu eine Urszene, die zwar noch nicht jene namensgebende von Freud vorwegnimmt, bei der das Kind den Geschlechtsakt seiner Eltern sieht oder phantasiert, die aber doch an die grossen Anfangsszenen der politischen Philosophie erinnert.

Ähnlich wie Hobbes, Rousseau, Locke und Kant mit Naturzuständen experimentiert haben, in denen Menschen in einer mythischen Vorzeit - will heissen vor ihrer Zivilisierung und Vergemeinschaftung - in diesen oder jenen Vertrag einwilligen, ersinnt auch Kierkegaard einen Einakter weit vor unserer Zeit, zumindest nach christlicher Zeitrechnung.

Die Szene entfaltet sich als Dilemma, das Gott den beiden Urmenschen Eva und Adam auferlegt. Es besteht im schlichten Verbot, vom Baum der Erkenntnis zu essen. Allerdings schenkt Gott mit dem Verbot den beiden uno actu die Freiheit, die letztlich eine Wahlfreiheit ist: Sie können den Apfel essen, dürfen es aber nicht. Erstmals in ihrem Leben haben Eva und Adam die Möglichkeit, etwas zu tun oder zu lassen, was weder notwendig noch unmöglich ist. Sie werden mit dem Verbot gleichsam aus ihrem vegetativen $\mathrm{Zu}$ stand befreit, indem ihnen die Möglichkeit gegeben wird, über sich selbst zu entscheiden. Kierkegaard zufolge ist dies der Moment, in dem der Geist sich erstmals selbst begegnet.

«Das Verbot ängstigt ihn [d. h. Adam], weil es in ihm die Möglichkeit der Freiheit weckt. Was als das Nichts der Angst an der Unschuld vorüberging, ist jetzt in ihn eingedrungen und ist nun wiederum ein Nichts, eine ängstigende Möglichkeit zu können.» (53)

Dilemmatisch ist das Angebot, da beide Handlungsoptionen mit einem schwerwiegenden Verlust einhergehen: Verzichten die Menschen darauf, vom Baum der Erkenntnis zu essen, erfahren sie nicht, was es heisst, frei zu sein. Essen sie hingegen vom Baum der Erkenntnis, ergreifen sie zwar die offerierte Freiheit, büssen aber ihre Unschuld ein. Freiheit und Unschuld sind zwei Werte, Güter oder Geschenke, die nicht beide empfangen werden können. Die Annahme des einen ist der Verlust des anderen. 


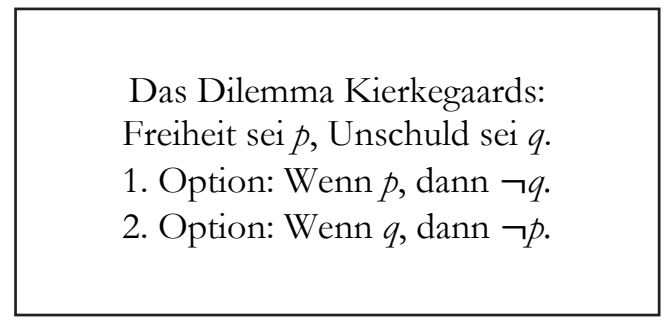

Abbildung 6: Das Dilemma Kierkegaards (eigene Darstellung).

Dieses Dilemma ist die Versuchsanordnung, aus der es für die ersten Menschen kein Entkommen gibt. Schlimmer noch: Das Dilemma wird für sie entschieden. Da sie das Verbot, vom Baum der Erkenntnis zu essen, als Verbot, etwas zu tun, verstehen, sind sie nolens volens zur Freiheit verdammt. Denn sie verstehen damit zugleich, dass sie es prinzipiell tun könnten. Selbst dann also, wenn sie entscheiden, nicht in den Apfel zu beissen, sind sie um ihre Unschuld gebracht. Die Freiheit führt unaufhaltsam und unerbittlich zum Verlust der Unschuld: wenn $p$, dann $\neg q$.

Übrigens: Im Protokoll, das den Gebrauch dieser Urszene zu Forschungszwecken reguliert, ist ausdrücklich festgehalten, dass es letztlich keine Rolle spielt, worauf sich das Verbot Gottes bezieht. Ob es Eva und Adam verboten ist, aus einem bestimmten Weiher Wasser zu schöpfen, einen spezifischen Baum zu fällen oder einen bestimmten Ort zu betreten, ist unerheblich. Unerheblich ist ebenso, ob es sich beim Baum der Erkenntnis um den Baum handelt, der Einsicht in das Gute oder Böse gewährt. Entscheidend ist nur das rein formal bestimmte Verbot, etwas Bestimmtes zu tun.

Tatsächlich dichtet Kierkegaard die Experimentalanordnung gegen jedes Entrinnen und jede Alternative ab. Zum einen gibt er dem Sündenfall eine Interpretation, die die Sünde hereinbrechen lässt, selbst wenn Eva und Adam die richtige Entscheidung getroffen hätten: «[D]urch das Verbot selbst, vom Baum der Erkenntnis zu essen, [wurde] die Sünde in Adam geboren.» (47) Zum anderen weist er fast erbost jede Skepsis an dieser notwendig verlaufenden Schadens- bzw. Sündensabwicklung zurück:

«Wenn ich hier einen Wunsch äussern dürfte, dann wollte ich wünschen, dass kein Leser so tiefsinnig wäre zu fragen: Und wenn Adam nun nicht gesündigt hätte? Im gleichen Moment, da [die Freiheit als die] Wirklichkeit gesetzt ist, geht die Möglichkeit nebenher als Nichts, das alle gedankenlosen Menschen in Versuchung führt.» (59) 
Wenngleich das Experiment keine empirischen Studien zulässt, ist Kierkegaard gleichwohl bestrebt, das schier tragische Ergebnis seiner Versuchsreihe «psychologisch〉 auszudeuten. Der Schluss liegt nahe: Der von der Freiheit verursachten Sünde entspricht psychologisch die Angst. Wie bereits erwähnt, verwendet Kierkegaard keine Mühe darauf, die Angst der Leserschaft so näherzubringen, dass sich mit ihr eine Bedeutung oder ein Sinn auch jenseits des Gedankenexperiments verbinden lässt. Die Angst bleibt, wie die beiden Urprobanden, eine Gefangene der aufwendigen Apparatur, mit der sie entdeckt worden ist. Dieser Umstand erlaubt es Kierkegaard freilich, die Angst zwar nicht als Gefühl, doch als Begriff präzise zu bestimmen.

\subsubsection{Die Geburt der Angst im Schosse der Freiheit}

Zunächst gibt sich die Angst als etwas zu erkennen, das ansatzweise mit dem übereinstimmt, was erst hundert Jahre später unter dem Begriff der «Angstlust» (Balint 1972) Beachtung in der Psychologie findet. Die «süsse Angst, die süsse Beängstigung» ist für Kierkegaard $(1992,51)$ jedoch nur ein Vorbote jener Angst, die erst mit dem Sündenfall sich ereignen wird. Als unschuldige Angst offenbart sie aber schon vorher die psychische Disposition, aus Lust an der Übertretung sich auf das Dilemma der Freiheit einzulassen: «Wenn man Kinder beobachtet, dann findet man diese Angst bestimmter angedeutet als ein Suchen nach dem Abenteuerlich-Märchenhaften, dem Ungeheuren, dem Rätselhaften.» (Ebd.) Die kindlich unschuldige Angst ist aber noch kein Resultat des Experimentalsystems, das ihre Probanden zwischen der Anode der Freiheit und der Kathode der Unschuld elektrisieren wird. Gleichwohl ist sie eine Bedingung dafür, dass der Geist die entscheidenden Stromstösse empfangen kann.

Damit das Experiment die fragliche Angst induzieren kann, muss das Urverbot explizit ausgesprochen werden. Wie bereits erwähnt, ist der Inhalt des Verbots irrelevant. Schliesslich kann, wie eine Vielzahl von Sagen und Märchen nahelegt, das fragliche Dilemma durch Untersagungen gänzlich anderen Inhalts erzeugt werden. In Vladimir Propps Morphologie des Märchens (1975) bildet das Verbot sogar eine der wichtigsten Funktionen des Märchennarrativs.

Mit der Aussprache des Urverbots entsteht in der Versuchsanordnung etwas gänzlich Neues. Und dieses lässt sich nicht auf die kindliche Angstlust reduzieren, das Verbot zu testen. Vielmehr erzeugt dieses die schiere Möglichkeit, überhaupt etwas zu können. Das Verbot ist die Geburt der Möglichkeit. Für das Verständnis dieser Möglichkeit ist es hilfreich, sie semantisch in die Nähe von Verben wie «vermögen», «imstande sein» oder «können» zu rücken. Das Verbot lässt somit eine Kontingenz im Sinne eines Könnens oder 
Vermögens entstehen, dem bislang die Unmöglichkeit oder die Notwendigkeit im Wege stand. «Die Möglichkeit besteht darin, zu können.» (Kierkegaard 1992, 59).

Das Verbot, diese gestrenge Hebamme des Könnens und Vermögens, besitzt eine zutiefst paradoxe Natur. Was den Sprechakt des Verbots betrifft, so hätte er eigentlich die Funktion, den Handlungsbereich einzuschränken. Und was das Subjekt seiner Äusserung anbelangt, müsste dieses einer Herrschaftsinstanz gleichkommen, die die Adressatinnen und Adressaten gleichsam degradiert. Doch das Verbot Kirkegaards bewirkt das genaue Gegenteil: Es ermächtigt die fraglichen Subjekte Eva und Adam, Mensch zu werden einerseits, wider das Gebot zu handeln andererseits.

Die Ermächtigung durch das Verbot erzeugt eine Form des Ur-Könnens oder des Ur-Vermögens, das freilich noch keine Ahnung hat, wie es sich verwirklichen will. Der frisch geborenen potentia entspricht eine Unwissenheit in mindestens zwei Belangen: Die Menschen wissen nicht, was sie nun tun können, und sie wissen ebenso wenig, welche Folgen ihr Tun hat (vgl. 53f.). Sie haben lediglich eine vage Ahnung von den Myriaden von Möglichkeiten, die ihr Vermögen nun bietet.

Und diese unwissende Ahnung stimmt mit der ersten Angst überein, die Kierkegaard in seiner Experimentalanordnung identifiziert. «In [dieser] Angst liegt die selbstische Unendlichkeit der Möglichkeit, die nicht wie eine Wahl verlockt, sondern betörend mit ihrer süssen Beängstigung ängstigt.» (73) Noch gibt es nichts, worauf sich das Vermögen als gestaltende Kraft beziehen könnte. Das Können steht noch in keinem Bezug zur Wirklichkeit, sondern geniesst ängstigend die reine Möglichkeit, die sich durch das Verbot eröffnet hat. Dieser ersten Angst entspricht noch nicht die Wirklichkeit, lediglich die Möglichkeit der Freiheit.

Die zweite Angst, die Kierkegaard aus seiner Urszene ableitet, taucht just im Übergang von der schieren Möglichkeit der Freiheit zu deren Wirklichkeit auf. An diesem Punkt taucht wie «im Sprung» die fragliche Angst auf, da es dem Können nun tatsächlich um seine Verwirklichung geht. «In einem logischen System sagt es sich recht leicht, dass die Möglichkeit in Wirklichkeit übergeht. In der Wirklichkeit ist dies schwieriger, da braucht es eine Zwischenbestimmung. Diese Zwischenbestimmung ist die Angst.» (59)

Diese zweite Angst ist der untrügliche Indikator für die Wirklichkeit der Freiheit. Will die Freiheit nicht nur als Möglichkeit bestehen, sondern gelebte Wirklichkeit werden, muss sie die Enge der Angst durchqueren. Damit macht sie sich endgültig schuldig: Sie entweiht eine paradiesische Ordnung mit 
menschlicher Kontingenz - eine Ordnung, die bis dato aus «natürlicher» Notwendigkeit und Unmöglichkeit bestanden hat. Ob der Baum der Erkenntnis seine Früchte verliert, ist nicht mehr eine Frage der Jahreszeit, sondern der menschlichen Willkür. Will die Freiheit sich verwirklichen, muss sie diese Passage der Angst durchlaufen - nun im Wissen darum, dass sie dabei die Falle der Sünde auslöst; an der ihre Unschuld sich verfangen wird.

\subsubsection{Die Angst und die Zukunft}

Noch bestimmt sich die Angst Kierkegaards gänzlich durch das teilweise subtile, teilweise brachiale Gedankenexperiment, in dem die ersten Menschen stellvertretend für alle kommenden Generationen ein Dilemma erfahren dürfen: Freiheit oder Unschuld - doch nicht beides zugleich. Das Verbot sorgt anschliessend für die Entscheidung von aussen. Wird es als Verbot verstanden, verlieren sie die Unschuld, erhalten aber im Gegenzug die Freiheit und mit ihr: die Angst. Kierkegaard hat mit diesem Experimentalsystem wahrlich so etwas wie die Angst entdeckt - weniger als nachvollziehbares Gefühl, wohl aber als Begriff. Und dieser lässt doch den weitreichenden Schluss zu: Wenn die Freiheit gefühlt werden könnte, sie wäre Angst.

Was in der Rezeption von Kierkegaards Angstschrift häufig übergangen wird, ist Kierkegaards eigenes Bemühen, die im Experiment detektierten Phänomene wie Freiheit, Sünde und Angst auch ausserhalb des Labors nachzuweisen. Doch da sie hierfür zunächst zu abstrakt sind, werden sie von Kierkegaard entsprechend kontextualisert und übersetzt. Tatsächlich gewinnt Kierkegaard aus der sterilen Freiheit der Urszene eine sogenannte historische Freiheit, die er mit Blick auf verschiedene Epochen unterschiedlich konturiert und besonders: unterschiedlich temporalisiert!

Indem er die Freiheit in ein inniges Verhältnis mit der Zeit bringt, schafft Kierkegaard nicht weniger als die diskursiven Bedingungen, unter denen der Begriff einer Zukunftsangst einen präzisen Sinn ergibt: «Im genauen und korrekten Sprachgebrauch sind daher Angst und Zukünftiges miteinander verknüpft.» (108)

Zum einen lässt Kierkegaard die erste Angst, dieses verheissungsvolle Gefühl für die Freiheit als Möglichkeit, sich auf alles Zukünftige beziehen. Die vage Ahnung einer schier grenzenlosen Freiheit wird somit zur süssen Angst vor der Zukunft, in der alles ohne jede Einschränkung möglich ist. Nur entspricht diese Angst einer Zukunft, die, um es mit Luhmann zu sagen, nicht beginnen kann (Luhmann 1976).

Zum anderen verortet Kierkegaard seine zweite Angst, welche die Freiheit als Wirklichkeit grundiert, just an dem Punkt, an dem die Zukunft in der 
Gegenwart beginnt. Es ist dies der Augenblick, in dem die Freiheit endlich die Wirklichkeit setzt und auf diese Weise die Zukunft an die Gegenwart bindet. Und dieser Augenblick ist jene Peripetie der Angst, in der die Freiheit in die Sünde umschlägt, da sie nun nicht mehr allein als Möglichkeit ersonnen, sondern verwirklicht wird.

Präzise beobachtet Kierkegaard vor dem Hintergrund dieser Zukunftsangst einen wichtigen Unterschied zwischen den beiden Urmenschen und ihren Nachfahren. Jene haben noch keine Vergangenheit, da diese erst mit dem Sündenfall beginnt. Sie sind deshalb ausserstande, sich an nicht verwirklichte Möglichkeiten zu erinnern. Erst die nachfolgenden Generationen vermögen einen Verlust an Möglichkeiten durch die Verwirklichung der Freiheit $\mathrm{zu}$ registrieren und zu antizipieren.

«Das höchste Maximum an Unterschiedlichkeit im Verhältnis zu Adam besteht darin, dass das Zukünftige vom Vergangenen antizipiert zu sein scheint, oder in der Angst, die Möglichkeit könnte verloren sein, bevor es sie gegeben hat.» (Kierkegaard 1992, 106)

Die Zukunftsangst umfasst nun auch die Verpassensangst.

\subsubsection{Kierkegaards Zukunftsangst}

In Kierkegaards Schrift Der Begriff Angst lassen sich mindestens drei unterschiedliche Zukunftsängste identifizieren, die allerdings fliessend ineinander übergehen.

Die erste Zukunftsangst entspricht einer Ehrfurcht für den unermesslichen Raum des künftig Möglichen. Sie ist eine süsse Beängstigung, in der Beklemmung durch und Lust auf das Kommende sich in der Schwebe halten.

Die zweite Zukunftsangst entspringt der Angst vor der Freiheit als Wirklichkeit. Sie akzentuiert den entscheidenden Übergang von der Kontingenz in Faktizität, von der Möglichkeit zur Wirklichkeit. Ihr gilt Kirkegaards ganze Aufmerksamkeit, da diese Angst das Subjekt mit sich selbst konfrontiert und in der Frage gipfelt: Was will ich tun? Welche der Myriaden von Möglichkeiten sollen für mich Wirklichkeit und damit auch Schicksal werden?

Die dritte Zukunftsangst ist eine vorauseilende Reaktion auf die zweite Zukunftsangst. Bevor das Subjekt seine Freiheit als Wirklichkeit setzt und sich so zu einer Möglichkeit bekennt, spielt die Verpassensangst vorsorglich schon einmal den Verlust der ausgeschlossenen Möglichkeiten durch. 


\subsection{Station II: Freud}

Ende des 19. Jahrhunderts erlangte der tschechische Kurort Marienbad dank der Anbindung an das Eisenbahnnetz ein Ansehen, das neben vielen anderen auch den späteren König Englands, Edward VII., bewog, in den dortigen Heilquellen zu neuen Kräften zu kommen. Marienbad war zu jener Zeit auch die Wirkungsstätte des umtriebigen Bäderheilkundigen und Gynäkologen Enoch Heinrich Kisch, der am Ruf des kleinen Städtchens tatkräftig mitwirkte, Vorlesungen an der Universität Prag hielt und ausserdem mehrere Werke zur Badewissenschaft und zur weiblichen Sexualität, darunter Die sexuelle Untreue der Fran (1917), verfasste. Hin und wieder wandte sich Kisch mit populärwissenschaftlichen Artikeln an das ganz grosse Publikum, die er in der Gartenlaube, dem Illustrirten Familienblatt, veröffentlichte und so nahezu 100000 Leserinnen und Leser erreichte.

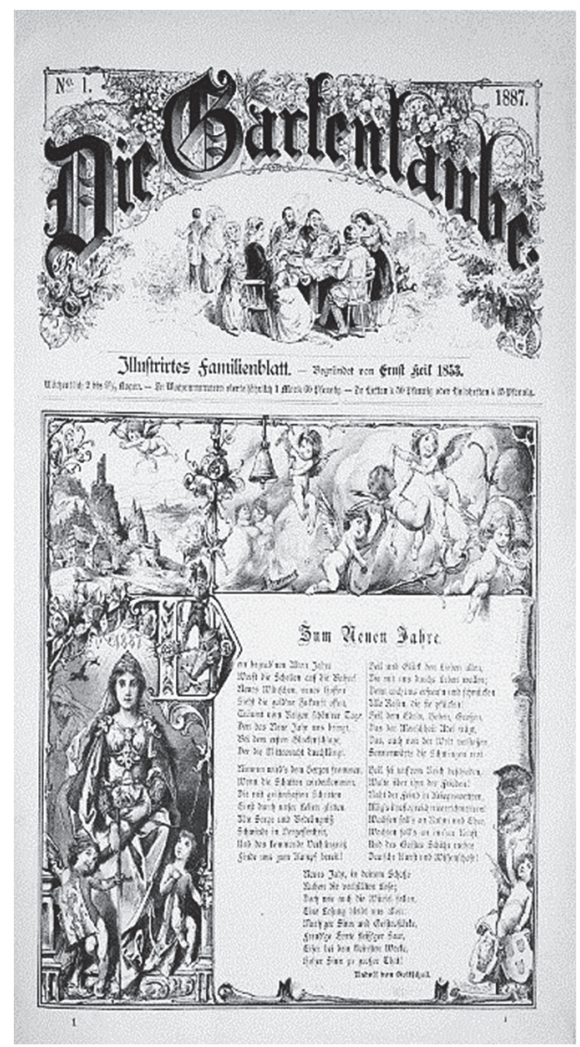

Abbildung 7: Titelseite von «Die Gartenlaube», No. 1 (Kisch 1887). 
Anfang des Jahres 1887 ist es wieder einmal so weit. In einem verhältnismässig langen Aufsatz unterrichtet Kisch (1887) die Leserschaft über Die Nervenschwäche (Neurasthenie). Gleich im ersten Absatz gibt der Balneologe das 19. Jahrhundert als das «Jahrhundert der Neurasthenie» aus. Lasse sich, so Kisch, der hier auf den französischen Historiker Jules Michelet anspielt, das 13. Jahrhundert als jenes der Lepra, das 14. Jahrhundert als jenes der Pest charakterisieren, ist die Krankheit, «die unserem Jahrhunderte eigenthümlich» ist, die der Nervenschwäche.

Selbst wenn das jüngste Klassifikationssystem der Krankheiten ICD-10 die Neurasthenie immer noch als Krankheit aufführt, hat sich Kischs Diagnose unbeabsichtigt bewahrheitet. Die Nervenschwäche ist, wenigstens aus heutiger Sicht, zu einer historischen Krankheit geworden: ein medizin- und sozialgeschichtlich gut erforschtes Phänomen, das bis zum Ausbruch des Ersten Weltkrieges währte und sich danach aus der Geschichte stahl. Das Zeitalter der Nervosität (Radkau 1998) kam nicht zuletzt an sein Ende, als das nervenschwächelnde Vokabular politisch gegen einen Wortschatz der Nervenstärke, des Mutes und der Tat eingetauscht wurde.

Möglicherweise ist die Neurasthenie auch aufgrund ihrer kaum zu bändigenden Diskursivität, die auf immer neue Symptome und Phänomene, ja auf eine kulturell breit abgestützte Beschleunigungserfahrung mitsamt ausgebremster Sexualität ausgriff, semantisch implodiert. Diese Sicht legt zumindest ein Holperreim von Otto Erich Hartleben nahe, der um 1900 die Neurasthenie ironisch um ihre Ernsthaftigkeit brachte: «Raste nie, doch haste nie, sonst haste die Neurasthenie.»

Ein paar Jahre früher wendet sich Sigmund Freud ebenfalls, wenn auch humorlos, gegen die überbordende diagnostische Fülle der Neurasthenie. In einer Schrift mit dem vertrackten Titel Über die Berechtigung, von der Neurasthenie einen bestimmten Symptomenkomplex als «Angst-Neurose» abzutrennen (1895) beanstandet Freud, der sich zu jener Zeit noch als Neuropathologe versteht, zunächst die Bedeutungsfülle des Namens Neurasthenie und schlägt alsbald als Lösung vor, von ihr den «Symptomkomplex der Angstneurose` abzutrennen.

Zwar hatte bereits zwei Jahre zuvor Ewald Hecker einen ähnlichen Angstkomplex beschrieben, ihn aber noch der Neurasthenie zugerechnet. Freud hingegen schält ein eigenständiges Krankheitsbild heraus, das er hinsichtlich Symptomatik sowie Herkunft (Ätiologie) von neurasthenischen Phänomenen abgrenzt. Nicht weniger als zehn Merkmale zeichnen die Angstneurose aus: Sie reichen von einer allgemeinen Reizbarkeit über eine ängstliche Erwartungshaltung und Schwindel bis hin zu Angstanfällen und nächtlichem 
Aufschrecken. Nachträglich gesehen ist Freud mit dieser breiten Symptomatik über das Ziel, eine homogene Angststörung freizulegen, hinausgeschossen. Angstanfälle gelten heute eher als Panik- und weniger als Angststörungen und sind dementsprechend medikamentös anders zu behandeln. Ähnliches gilt für manche Phobien, die Freud noch der Angstneurose unterschiebt.

Dennoch hat Freud mit der «ängstlichen Erwartung» ein Kriterium für jene Angststörung freigelegt, die heute als Generalisierte Angststörung (engl. Generalized anxiety disorder) grosszügig diagnostiziert (vgl. Abb. 3) und bisweilen als die grundlegende Angststörung angesehen wird (Brown u. a. 2001). Aufgrund der eindringlichen Beschreibung dieser Erwartungshaltung lohnt es sich, sie hier ausführlich wiederzugeben:

«Ich kann den Zustand, den ich meine, nicht besser erläutern als durch diesen Namen und einige beigefügte Beispiele. Eine Frau z. B., die an ängstlicher Erwartung leidet, denkt bei jedem Hustenstosse ihres katarrhalisch affizierten Mannes an Influenzapneumonie und sieht im Geiste seinen Leichenzug vorüberziehen. Wenn sie auf dem Wege nach Hause zwei Personen vor ihrem Haustor beisammenstehend sieht, kann sie sich des Gedankens nicht erwehren, dass eines ihrer Kinder aus dem Fenster gestürzt sei; wenn sie die Glocke läuten hört, so bringt man ihr eine Trauerbotschaft u. dgl., während doch in allen diesen Fällen kein besonderer Anlass zur Verstärkung einer blossen Möglichkeit vorliegt.» (Freud 1895, S. 62).

Für die fraglichen Patienten geht diese ängstliche Zukunftsorientierung über ein Mass hinaus, das sie noch zu kontrollieren imstande sind. Sie begegnet ihnen als Zwang, von dem sie partout nicht ablassen können. In freier Paraphrase begegnet ängstlich Erkrankten die Zukunft nicht als «horizontaler» Horizont, der sich beim Nahen immer weiter in den Raum hinausschiebt, sondern als vertikaler oder negativer Horizont, der bei seiner Näherung immer mehr den Blick in den Abgrund freigibt. Kierkegaards alpinistisch anmutender Schwindel der Freiheit erfährt in Freuds Angstneurose sein urbanes und doch mittelalterlich wirkendes Gegenstück in Gestalt des horror vacui.

Es ist eine knappe und beiläufig wirkende Bemerkung, die Freud seiner Beschreibung der ängstlichen Erwartung anhängt, die sich für die Rezeption der Angstneurose im 20. Jahrhundert noch als folgenreich erweisen wird. Deren genaue Bedeutung lässt sich im Text kaum erschliessen, doch das darin enthaltene Wortpaar «frei flottierend» wird nicht nur einige Jahrzehnte danach die (post)strukturalistische Theoriebildung entzücken, sondern auch die Psychiatrie und deren Klassifikationssysteme für lange Zeit beschäftigen. 
«Man kann etwa sagen, dass hier [bei der ängstlichen Erwartung] ein Quantum Angst frei flottierend vorhanden ist, welches bei der Erwartung die Auswahl der Vorstellungen beherrscht und jederzeit bereit ist, sich mit irgendeinem passenden Vorstellungsinhalt zu verbinden.» (Freud 1895, S. 65, Hervorhebung im Original)

\subsubsection{Die Entdeckung der Angst}

Gemessen an der heutigen Differenzialdiagnostik der Angststörungen, wie sie im DSM-5 (Diagnostic and Statistical Manual of Mental Disorders) und in dem sämtliche Krankheiten umfassenden Klassifikationssystem ICD-10 zu Protokoll gebracht wird, darf Freud die Entdeckung einer pathologischen Angststörung zuerkannt werden, die sich durch drei Merkmale auszeichnet, die heute noch für den Befund einer Generalisierten Angststörung verwendet werden:

1) eine pessimistische Zukunftsorientierung, für die kein Anlass in der Gegenwart in Form einer akuten Bedrohung besteht;

2) ein Sorgen um künftige Dinge, das für die betroffenen Patienten nicht kontrollierbar und zwanghaft ist;

3) ein freies Flottieren der Inhalte, auf die das ängstliche Erwarten sich bezieht.

Knapp fünfzig Jahre vor Freuds Absonderung der Angstneurose hat Kierkegaard in einer aufwendigen Experimentalordnung einen Begriff von Angst isoliert, für den es im Gefühlsleben der damaligen Zeit noch keine wirkliche Entsprechung gab. Er siedelte die Angst begrifflich dort an, wo sich ein Subjekt für eine Freiheit als künftige Wirklichkeit entscheidet und damit unzählige andere Möglichkeiten, sein Leben zu führen, ausschliessen muss. Dieser philosophisch überhöhte Angstbegriff scheint in Freuds Angstneurose endlich ein emotionales, wenngleich pathologisches Korrelat gefunden zu haben.

Natürlich liegt der Einwand auf der Hand, wonach die beiden Angstkonzepte nur wenig gemein haben und durch kein historisches und emotionales Band miteinander verbunden sind. Tatsächlich lassen sich zwischen den beiden Angstkonzeptionen nur zufällig wirkende Überschneidungen feststellen: In beiden Fällen ist die Rede von einem Schwindel, in beiden Schriften geht es um künftige Möglichkeiten und bei beiden Autoren gibt es eine Form des Durchspielens oder Flottierens von Angstinhalten. Diese Ähnlichkeiten vermögen eine positivistisch gestimmte Skepsis kaum zu beruhigen. Allerdings muss sich diese das Argument gefallen lassen, dass sie sich um eine Einsicht bringt, die den mannigfaltigen und ausufernden Angstdiskursen eine historische Ordnung abgewinnt: Spätestens seit Kierkegaard nämlich schickt sich eine Angst an, sich auszudifferenzieren, deren Gegenstand die Zeit, genauer 
die Zukunft ist. Und als solche grenzt sie sich von Ängsten ab, die wie die Scham die soziale Sinndimension oder die wie die Phobien die sachliche Sinndimension bevölkern.

Selbstverständlich findet diese Ausdifferenzierung im Spannungsfeld von Entdeckung und Erfindung statt: Denn die Texte, in denen diese Angst an die Oberfläche tritt, sind aufwendige Apparaturen aus Gedankenexperimenten, Begriffen, Methoden, Gesprächen und Theorien - intellektuelle Maschinerien, die, jenen der Naturwissenschaften nicht unähnlich, das erschaffen, was sie zu entdecken vorgeben. Ob es sich hierbei um elektrische Phänomene oder Gefühle handelt, bedeutet für die Perspektive einer historischen Ontologie keinen kategorialen Unterschied.

Vor diesem Hintergrund lässt sich erneut ermessen, wie Freud die neurotische Angst gleichermassen entdeckt und erfindet. Mit den drei oben genannten Merkmalen der Angststörung ist er, nimmt man die heutige Diagnose einer Generalisierten Angststörung als Massstab, tatsächlich einer Angst auf der Spur, die weit weniger als bei Kierkegaard den Eindruck von Erfindung macht. Trotzdem ist die entdeckte Angstneurose in vielen Aspekten noch $\mathrm{zu}$ amorph und $\mathrm{zu}$ frei flottierend, um sie bei Patientinnen und Patienten zweifelsfrei identifizieren zu können. Die Angstneurose zeichnet sich zu diesem frühen Zeitpunkt durch eine interpretative Flexibilität aus, die in vielen Patientengesprächen und Texten noch zu bewältigen sein wird. Tatsächlich wird Freud im Anschluss zwei unterschiedliche Angsttheorien entwerfen, die ihn allerdings selbst in den späten Vorlesungen (Freud 2006b [1933]) noch nicht zufriedenstellen werden. Diese beiden Theorien sind die eigentlichen Erfindungen bzw. Konstruktionen, mithilfe derer die Angst getestet, fragmentiert und differenziert wird.

Auf zwei Ergebnisse dieser konstruktiven Theoriearbeit sei hier vorgegriffen. Erstens gelangt Freud dank des Strukturmodells, das die Psyche in die drei Instanzen von Ich, Über-Ich und Es gliedert, zu einer Unterscheidung verschiedener Angsttypen, die sich weitgehend mit jenen decken, die hier als Ergebnisse eines allmählichen Ausdifferenzierungsprozesses der Angst in der sachlichen, sozialen und zeitlichen Dimension behauptet werden.

«Das Leben ist nicht leicht! Wenn das Ich seine Schwäche einbekennen muss, bricht es in Angst aus, Realangst vor der Aussenwelt, Gewissensangst vor dem Über-Ich, neurotische Angst vor der Stärke der Leidenschaften im Es.» (Freud 2006b, 1104f.)

Freuds Dreiteilung der Angst kommt der hier verfolgten These einer Modernisierung und Spezialisierung der Angst erstaunlich weit entgegen: 
Sachliche Dimension: Realangst

Soziale Dimension: Sozial- oder Gewissensangst wegen Über-Ich Zeitliche (?) Dimension: neurotische Angst wegen Es

Das Fragezeichen bei der zeitlichen Dimension verdient besondere Beachtung. Denn es verweist auf das zweite und letztlich unbefriedigende Ergebnis von Freuds Theorie- und Begriffskonstruktionen. Denn sämtliche von Freuds Schriften, die sich der neurotischen Angst widmen, rücken die ängstliche Erwartung und die pessimistische Zukunftsorientierung als Merkmale in den Vordergrund. Doch beharrlich weist ein ätiologisches Begehren - ein, so will es scheinen, bildungsbürgerlich anmutendes Ursprungsdenken - dieses Überborden der Möglichkeiten des Es in seine Schranken. Der neurotischen Angst wird nicht erlaubt, frei und ungebunden wie bei Kierkegaard sich an der Zukunft zu reiben. Sie wird stattdessen ständig auf etwas zurückgebogen und zurückgefaltet, das als ursprünglicher Angstauslöser in der Vergangenheit der Psyche liegt und das die Angsterwartungshaltungen mit Blick auf neue Situationen vorherbestimmt. Angst vor der unbekannten Zukunft mutiert also unter der Hand zu einer Variation oder einem Signal einer ursprünglichen Angst, die in der Konfrontation mit einem traumatischen Erlebnis erworben wird.

«Die Affektzustände sind dem Seelenleben als Niederschläge uralter traumatischer Erlebnisse einverleibt und werden in ähnlichen Situationen wie Erinnerungssymbole wachgerufen.» (Freud 2015, 239)

Auch die neurotische Angst, die Angst vor einer unbekannten Zukunft, hat sich diesem anamnetischen Modell zu fügen. Angst ist, in freier Anspielung auf Platons Erkenntnistheorie, Wiedererinnerung. Damit entwertet Freud die Inhalte der neurotischen Angst, die sich pessimistisch und frei flottierend auf das Noch-nicht der Zukunft beziehen.

Zwar operiert auch Kierkegaard mit einer Urszene, um die Genese der Freiheit jenseits von Notwendigkeit und Unmöglichkeit zu erklären. Allerdings stehen die beiden Protagonisten jenes Gedankenexperiments, Adam und Eva, in einem hypothetisch-begrifflichen und damit weder kausalen noch historischen Verhältnis zu jenen Menschen, die im 19. Jahrhundert beginnen, sich vor der Zukunft zu ängstigen. Freuds Ambitionen hingegen, der neurotischen Angst mit einer Theorie zu begegnen, verführen ihn ständig dazu, unter Theorie Ätiologie zu verstehen: psychokausale Ursprungsforschung. 


\subsubsection{Die Erfindung der Angst}

Freuds erste Angsttheorie führt die neurotische Angst wenig missverständlich auf libidinöse Spannungen zurück. Wird die Libido entgegen ihrer normalen Verwendung blockiert und abgelenkt (2006a, 1001), entsteht als Abfuhrreaktion Angst. Mehr als die Erklärung interessiert aber zunächst die Frage, wozu Freud überhaupt eine Theorie braucht. Wenn eine angestaute Libido, wie sie nach dem coitus interruptus, dem Klimakterium, der sexuellen Abstinenz, der Masturbation und anderen Unterbrechungen (Freud 1895) auftritt, die Antwort ist, was ist dann die Frage?

In seinen früheren Vorlesungen (Freud 2006a [1916/17]) trifft Freud eine Unterscheidung, die an jene Kierkegaards zwischen Furcht und Angst erinnert, sie aber zugleich psychoanalytisch vertieft. Differenziert wird zwischen neurotischer Angst und Realangst. Während Freud wie bisher die Angstneurose mit einer «frei flottierenden Erwartungsangst» gleichsetzt, versteht er unter Realangst in erster Linie die zahlreichen Phobien, die psychisch gebunden und an gewisse Objekte und Situationen wie offene Plätze, Spinnen, Schlangen, Mäuse, See- und Eisenbahnfahrt geknüpft sind (a. a. O., 996). ${ }^{2}$

Im Gegensatz zu Kierkegaards Angst sind die zahlreichen Phobien zwar mit Objekten assoziiert, aber doch pathologischer Natur. Denn der durch sie hervorgerufene Angstzustand ist alles andere als zweckmässig, da er die phobisch Erkrankten an einer rationalen Reaktion hindert - einer Reaktion, die in kühler Risikoerwägung und gegebenenfalls Flucht bestehen müsste. Freud erwägt, ob der lähmende Zustand nicht im Geburtsakt erlernt wird, in dem das Neugeborene sich einerseits von seiner Mutter lösen, andererseits auf eine äussere Atmung umstellen muss. Diese erste «toxische» Lebensgefahr avanciert gleichsam zum Vorbild für kommende Situationen, in denen eine Bedrohung von Leib und Leben befürchtet wird (Freud 2006a, 995).

Sieht man von dieser waghalsigen Ätiologie der Realangst ab, bleibt für sie und die pathologisch zugespitzten Phobien ein Bezug zu Situationen oder Objekten, zu bestimmten Gefahren also bestehen. Nur: Dieser Objektbezug ist im Fall der neurotischen Angst nicht gegeben. In ihrem freien Flottieren ist sie bereit, sich an jeden irgendwie passenden Vorstellungsinhalt anzuhängen. Es ist dieser Mangel oder Überschuss an Gefahren, der Freud veranlasst, für die neurotische Angst eine Theorie zu entwickeln.

2 Die Phobien werden aus unerfindlichen Gründen mal eher auf die Seite der Real-, mal auf die Seite der neurotischen Angst geschlagen. Da sich kein triftiger Hinweis auf eine Verwandtschaft der Phobien mit der Angstneurose findet, tauchen sie hier konsequent als pathologische Formen der Realangst auf. 
«Wir werden doch zunächst die Erwartung festhalten wollen: wo Angst ist, muss auch etwas vorhanden sein, vor dem man sich ängstigt.» (Freud 2006a, 998)

Die Erklärung, die Freud für die Angstneurose letztlich anbietet, besteht in einer Internalisierung des ängstigenden Objektes, das im Anspruch der Libido gefunden wird. Wenn die Libido durch moralische oder gesellschaftliche Konflikte an ihrer freien Entfaltung gehindert wird, staut sie sich auf und verwandelt sich in Angst. Diese energetische Transformation begreift Freud als einen somatischen Vorgang, der nicht psychologisch, sondern physiologisch aufzuklären ist. Tatsächlich verwendet der damals noch neuropathologische Freud noch einige Mühen darauf, diesen Prozess als Druck der Samenbläschen auf ihre Nervenenden zu beschreiben - ein Druck, der bei einem bestimmten Quantum den Reiz an die Hirnrinde weitergibt und dort den psychischen Reiz libidinöser Anspannung auslöst.

Die moralische oder kulturelle Inhibierung der Libido führt dann zu einem Fluchtversuch des Ichs vor diesem Trieb oder Anspruch. Der Gegenstand, wovor sich also die neurotische Angst zu guter Letzt ängstigt, ist die eigene Libido, für die dann frei flottierende Angstinhalte gesucht werden müssen.

«[D]a liegt uns denn die Auffassung nahe, dass bei der neurotischen Angst das Ich einen ebensolchen Fluchtversuch vor dem Anspruch der Libido unternimmt, diese innere Gefahr so behandelt, als ob sie eine äussere wäre.» (Freud 2006a, 1001)

Diese erste Angsttheorie macht bereits auf Freuds problematisches, da alles erklärendes Ursprungsdenken aufmerksam. Es nimmt die Zukunftsorientierung der neurotischen Angst nicht wirklich ernst und führt sie stattdessen auf den Gegenstand namens Libido zurück, der in keinem ersichtlichen $\mathrm{Zu}$ sammenhang mit der «ängstlichen Erwartung» steht, die Freud selbst als das entscheidende Merkmal der neurotischen Angst ausgeben hat.

Diese Schwierigkeit ist auch in Freuds zweiter Angsttheorie anzutreffen eine Theorie, die aber in anderen Hinsichten überaus aufschlussreich ist. Sie kommt erstmals in Freuds Schrift Hemmung, Symptom und Angst aus dem Jahre 1926 zum Ausdruck, in der drei grössere Revisionen der ersten Theorie vollzogen werden. Erstens prägt fortan das Strukturmodell der Psyche, d. h. ihre Unterteilung in Ich, Über-Ich und Es, das Nachdenken über Angst. Zweitens lässt Freud die energetische Konversionsthese fallen: Die neurotische Angst entsteht nicht mehr aus einer Verdrängung und Umwandlung der Libido in 
Angst - wenn schon umgekehrt. Die Angst bringt das Ich dazu, sie zu verdrängen. Drittens führt Freud die Unterscheidung zwischen einem Angstsignal und einem traumatischen Moment ein.

Zunächst ordnet Freud die Angst dem Ich zu, da nur dieses in der Lage ist, Angst zu empfinden: «das Ich ist die alleinige Angststätte», wird Freud in den späten Vorlesungen (Freud 2006b [1933], 1109) wiederholen. Da das Ich als Organisationseinheit von einer Aussenwelt, einem gewissenhaften ÜberIch sowie einem triebhaften Es abhängig ist, entstehen an diesen Nahtstellen Konflikte, die sich unter anderem als Angst äussern. Realangst ist ein Signal auf eine problematische Beziehung zur Aussenwelt; die Gewissensangst, die sich im Erwachsenenalter zur Sozialangst auswachsen wird, ein Hinweis auf eine Kontroverse mit dem Über-Ich und die neurotische Angst schliesslich ein Indikator für einen Unfrieden mit dem Es.

Besonders am Beispiel der Gewissensangt gewinnt die Bestimmung der Angst dank des Strukturmodells einiges an Plausibilität - sieht man von der Kastrationsangst ab, die sich aber verlustlos durch eine weniger kryptische Angst ersetzen lässt. Kandidaten hierfür wären die Angst vor Liebesentzug oder jene vor sozialer Degradierung.

«Wie das Über-Ich der unpersönlich gewordene Vater ist, so hat sich die Angst vor der durch ihn drohenden Kastration [bzw. Herabsetzung, M. K.] zur unbestimmten sozialen oder Gewissensangst umgewandelt. Aber diese Angst ist gedeckt, das Ich entzieht sich ihr, indem es die ihm auferlegten Gebote, Vorschriften und Busshandlungen gehorsam ausführt.» (Freud 2015 [1926], 270f.)

Unabhängig davon, ob es der Vater, die Mutter oder die Gesellschaft ist, die da im Über-Ich internalisiert wird, diese Instanz bedroht ständig das Ich mit Liebesentzug, mit sozialer Herabsetzung und, wer unbedingt daran festhalten möchte: mit Kastration. Auf diese Ängste reagiert das Ich durch bewusste oder unbewusste Bewältigung der Angst in Form von Lernen (später: coping) oder Verdrängen.

Gerade bei der neurotischen Angst zeigt sich in der neuen Theorie, dass diese nicht das Resultat, sondern die Bedingung für eine Verdrängungsleistung ist. Angst entsteht also nicht durch ein Unterdrücken, Verdrängen oder Stauen der Libido, sondern taucht als Effekt der Libido selbst auf. Denn das Ich antizipiert die Konflikte, die ein ungebremstes Es verursachen würde, und ängstigt sich entsprechend vor ihnen. In der Phase des Ödipuskomplexes etwa nimmt das Kind angstvoll die Konsequenzen vorweg, die aus seiner Verliebtheit in die Mutter resultieren könnten. Mit dieser Konzeptualisierung gleicht Freud die neurotische Angst der Realangst an, da erstere ebenfalls auf 
eine äussere Gefahrensituation reagiert, die infolge einer entfesselten Libido zu erwarten ist. Das Ich ängstigt sich also nicht mehr vor der Libido selbst, sondern vor ihren möglicherweise verheerenden Auswirkungen.

Freud lässt es bei dieser Erklärung nicht bewenden. Er schiebt ihr noch eine Unterscheidung nach, die den Angstzustand, der jeweils in Gefahrensituationen empfunden wird, in einem anamnetischen Verhältnis zwischen einem ursprünglichem Trauma und einem Signal, das auf diesen Ursprung verweist, fundieren möchte. ${ }^{3}$ Als traumatische Momente gelten Freud Situationen tiefer Ohnmacht und Hilflosigkeit, in denen der Reizschutz des Ichs durchbrochen wird. Das Ich wird von Erregungen überflutet, die es nicht mehr mithilfe des Lustprinzips zu bewältigen weiss. Infolge der Verdrängung traumatischer Urerlebnisse, für die der Geburtsakt nach wie vor das Vorbild ist, entsteht in aktuellen Gefahrensituationen eine Angst, die als Signal für oder als Erinnerung an die ehemals erlittene Ohnmacht fungiert. Die Angst hat, so folgert Freud, «eine zweifache Herkunft»:

«einmal als direkte Folge des traumatischen Moments, das andere Mal als Signal, dass die Wiederholung eines solchen droht» (Freud 2006b, 1116).

\subsubsection{Freuds neurotische Angst}

Im Rahmen seiner Auseinandersetzung mit der Neurasthenie entdeckt Freud einen eigenständigen Symptomkomplex, den er neurotische Angst tauft. Neben einer Vielzahl anderer Merkmale zeichnet sie sich vorwiegend durch eine «ängstliche Erwartung» sowie ein «freies Flottieren» der Angstinhalte aus. Tatsächlich spricht vieles dafür, dass es Freud gelungen ist, in der Ökonomie der Gefühle am Ende des 19. Jahrhunderts eine Angst freizulegen, die sich von anderen Ängsten und Phobien deutlich abhebt. Dass es sich hier um eine Entdeckung eines bis heute existierenden Emotions handelt, belegt zudem die heute weitverbreitete Diagnose einer Generalized anxiety disorder, die ihrerseits das freie Flottieren und die ängstliche Erwartungshaltung in ihrem Kriterienkatalog führt.

Dank des Strukturmodells von Ich, Über-Ich und Es kommt Freud zu einer Differenzierung, die Ordnung in das bislang schlecht organisierte Orchester der Angst bringt. Realängste, Gewissens- und Sozialängste sowie die neurotische Angst bilden nun für sich abgeschlossene Angstphänomene, denen unterschiedliche Konflikte zugrunde liegen: mit der Aussenwelt, mit

3 Freud greift hier die Unterscheidung auf, die er und Breuer schon Jahrzehnte zuvor am Fall der Hysterie erarbeitet haben(Freud/Brenet 1893). 04.2023, 12:38:07 
dem Über-Ich sowie mit dem Es. Mit dieser Differenzierung kommt Freud tatsächlich der hier gesuchten historisch gewendeten Ausdifferenzierung der Angst sehr nahe.

Einzig die neurotische Angst, die Freud durch die Jahrzehnte hindurch am meisten Rätsel aufgibt, findet noch nicht den Platz, den sie später als temporal ausdifferenzierte Angst, als Zukunftsangst einnehmen wird. Es wirkt, als ob ein Ursprungsdenken Freud davon abhält, die schiere Phänomenologie der neurotischen Angst - ihr zwanghaft anmutendes Durchspielen von allem künftigen Unheil - tatsächlich ernst zu nehmen. Statt die neurotische Angst auf die Zukunft zu beziehen, wird sie in der Vergangenheit fundiert und verankert.

Erst Martin Heideggers Werk Sein und Zeitvon 1927, ein Jahr nach Freuds Hemmung, Symptom und Angst publiziert, sucht den Grund für die Angst nicht mehr in traumatischen Urerlebnissen in der Vergangenheit, sondern in einem Trauma, das allen bevorsteht: der eigene Tod.

\subsection{Station III: Heidegger}

Für die Philosophie waren die 1920er-Jahre Gründerjahre. 1922 erscheint Ludwig Wittgensteins Tractatus logico-philosophicus, der die Sprachphilosophie angelsächsischer Prägung ins Leben rufen wird. 1923 kommt Georg Lukács' Essaysammlung Geschichte und Klassenbewusstsein auf den Ladentisch. Sie wird zur Keimzelle des westlichen Marxismus, wie er sich später bei Marcuse, Horkheimer oder Adorno manifestiert. Und schliesslich erscheint 1927 Heideggers Werk Sein und Zeit, das die Phänomenologie und Existenzphilosophie besonders in Frankreich befruchten wird.

Die drei Werke sind so unterschiedlich, dass sie zunächst kaum Gefahr laufen, offen miteinander in Konkurrenz zu treten. Erst die nachfolgenden Apologeten einer Sprach-, Sozial- und Existenzphilosophie werden sich das Leben gegenseitig schwer machen. Den Auftakt macht Theodor W. Adornos Essay Jargon der Eigentlichkeit (1964), der in gut ideologiekritischer Manier mit der Sprache im Nachkriegsdeutschland ins Gericht geht - einer Sprache, die immer noch jenen Jargon aufweise, der dem Faschismus Asyl gewährte (a. a. O., 9). Zum Jargon gehören «marktgängige Edelsubstantive», die zwar eine emphatische, ja sakrale Wahrheit beanspruchen, diese aber aufgrund der Leere und Austauschbarkeit von Signalwörtern wie «Anliegen», «Anruf» und «Begegnung» niemals werde einlösen können. Unter dem Stichwort der «Eigentlichkeit» kommt Adorno sodann auf Heidegger selbst zu sprechen, dessen Sein und Zeit er für die Quelle der pseudoreligiösen Sprache verantwortlich macht. Besonders auf den zweiten Teil von Heideggers Werk, auf 
das grosse Todeskapitel, zielt Adornos Kritik. Er begreift Heideggers These, wonach in unserem Verhältnis zum Tod unsere Existenz als ganze erfahrbar werde, nicht als eine Analyse der Faktizität des Todes, sondern als dessen Verklärung und Theodizee (a. a. O., 111).

Tatsächlich ist Adorno in allen Punkten recht zu geben. Die Terminologie von Seit und Zeit ist oft erschreckend altertümelnd und eigentlichkeits-versessen. Und das Todeskapitel favorisiert zuweilen eine Haltung gegenüber dem Tod, die «das Sein zum Tode» jenem Ernst Jüngers angleicht, dessen Soldaten sich offenen Herzens und frohen Mutes in die Stahlgewitter stürzen.

Wer allerdings an einer Geschichte der Zukunftsangst herumdoktert, kommt an Sein und Zeit kaum vorbei. Dessen Maschinerie, die mehr an ein grobes Mahlwerk als an einen sorgfältig verdrahteten Detektor erinnert, biegt nicht nur die Bedeutung etlicher Begriffe der philosophischen Tradition gewaltsam um, sondern bringt Angst und Zeit in ein so enges Verhältnis, dass es auch von Kierkegaard kaum vorhergesehen werden konnte. Um es vorwegzunehmen: Die Angst erschliesst sich ihre Zukunft von ihrem Ende, dem künftigen Tod, her.

Nach Sein und Zeit und nach der sogenannten Kehre ist für die Angst in Heideggers Denken kein Platz mehr vorgesehen. Als Wort oder Begriff taucht sie in den nachfolgenden Schriften kaum mehr auf - was auch kaum verwunderlich ist, da diese möglichst kompromisslos die Subjekt- und Bewusstseinsphilosophie des Frühwerks hinter sich lassen möchten. Durch die Verabschiedung des fühlenden und denkenden Subjekts geht also der Angst auch ihr Sitz in Herz und Geist verloren. Auf den ersten Blick. Auf den zweiten jedoch spukt und flottiert sie weiterhin frei in den Texten herum, ohne dass aber von ihr explizit die Rede wäre. Was nährt diesen Verdacht?

Die philosophische Leistung von Sein und Zeit war es, dem entrückten und unsterblichen Subjekt der Bewusstseinsphilosophie einerseits eine Welt, andererseits eine Zeit vermacht zu haben. Dem in seinem Denken und Erkennen vereinsamten Menschen kam bis dahin bloss ein zwar nobler, aber ebenso distanzierter Beobachterstatus zu: Er durfte die Wirklichkeit in sicherer Entfernung interpretieren, deuten und nach seinen Kategorien zurechtlegen, auf keinen Fall aber in sie eingreifen und sie mit Händen und Werkzeugen umgestalten. Dieses Verhältnis zwischen Mensch und Welt, das noch stark an die antike Theorieidee von Zuschauer und Bühne gemahnt, löst Heidegger zugunsten eines settings auf, in dem der Mensch sich inmitten einer mehr oder minder übersichtlichen Welt wiederfindet. Hier begegnen ihm die Dinge nicht mehr als vereinzelte Objekte, die er wie ferne Gestirne durch einen Operngucker begutachtet, sondern in Myriaden von Abhängigkeiten 
untereinander. Ein Hammer, für die traditionelle Bewusstseinsphilosophie kaum mehr als ein Gegenstand aus Holz und Eisen, nimmt nun die Gestalt eines Zeugs an, das zum Einschlagen von Nägeln dient, die wiederum Bretter zusammenhalten, mit denen sich eine Kiste bauen lässt, in die Spielsachen versorgt werden können usw.

Zudem vermittelt Heidegger dem Subjekt eine Zeitlichkeit, die tief greifend seine Stimmungen und seine Wahrnehmungen prägt. Getaktet wird das Zeitbewusstsein durch die Sterblichkeit. Da der bevorstehende Tod dem Subjekt zwar Zeit, aber keine Ewigkeit einräumt, empfängt es einerseits ein spezifisches Gefühl für all die Möglichkeiten, die ihm noch offenstehen. Gerade weil es nicht ewig lebt, entwirft es sich fortwährend in die Zukunft, um sich in der einen oder anderen Weise sub specie mortis zu verwirklichen. Andererseits markiert das Ende des Lebens zugleich einen Reflexions- und Zeitpunkt, von dem aus die eigene Geschichte als Vergangenheit allererst erfahrbar wird.

Innerhalb dieses für die damalige Philosophie überraschenden Gefüges von Welt und Zeit, in welches das Subjekt unentwirrbar verflochten ist, kommt der Angst eine buchstäblich existenzielle Bedeutung zu. Denn sie konfrontiert den Menschen mit seinem künftigen Ende in einem Masse, dass darob die gesamte Welt zusammenbricht. Sie verliert im Zustand der Angst ihre gesamte Bedeutsamkeit: Es spielt nun schlicht keine Rolle mehr, wozu ein Hammer gut ist, wozu wir Geschenke für Verwandte einkaufen oder wozu wir uns für ein Date fein herrichten. Mehr noch: Alle diese noch unerledigten Sinnbezüge, diese to-dos und Verpflichtungen sind das, wovor der Angst graut. Sie erblickt darin Bedrohungen und Gefahren für die Möglichkeit, sich möglichst befreit von aktuellen Verbindlichkeiten in die Zukunft zu entwerfen, um, wenn immer möglich, dem Tod eine saubere Rechnung über den eigenen Willen präsentieren zu können. Der Grund der Angst liegt nun nicht mehr wie bei Freud in einer traumatischen Vergangenheit begraben, sondern antizipierend in einer Zukunft, die aber zugleich ihr Ende anzeigt. In der Denkfigur einer Angst, die sich die Zukunft von ihrem Ende her erschliesst, ist der Samen jener Zukunftsangst angelegt, die verborgen auch in Heideggers späteren Schriften herumgeistert und die zudem all den chronopolitischen Manövern der heutigen Zeit ihre raison d'être verleiht.

Nach Sein und Zeit gibt Heidegger die Existenzphilosophie weitgehend auf. Es geht ihm fortan nicht mehr um die Frage, wie ein Subjekt bzw. ein Dasein sich seine Welt und sein Leben erschliesst, sondern um die übergeordnete, wie die Geschichte das Verhältnis zwischen Mensch und Welt gestaltet und verändert. Dem Subjekt kommt nun nicht mehr die alleinige 
Kompetenz der Weltauslegung zu, da hinter seinem Rücken eine Seinsgeschichte epochenabhängig vorspurt, wie es sich selbst und die Welt zu verstehen hat. Trotz dieses aufwendigen Umbaus der Existenzphilosophie zu einer temporalisierten Metaphysik und trotz der Tilgung des Subjekts bleiben spezifische Denkstrukturen erhalten. Mit Blick auf die Zukunftsangst besonders relevant: das Vorlaufen zum Tode. Dieses Motiv taucht nun nicht mehr im Kontext des individuellen, sondern eines ominös kollektiv gedachten Ablebens auf. Da Heidegger die Seinsgeschichte ausgehend von den Vorsokratikern bis zum Gestell der Technik als eine grandiose Verfallsgeschichte konzipiert, laufen wir Menschen unaufhörlich auch auf ein Ende zu, das uns zwar nicht mit dem Tode, sondern mit dem Nichts überrascht.

Es gibt freilich noch einen weiteren und zutiefst fragwürdigen Gedanken, den Heidegger aus Sein und Zeit in die neue Untergangsgeschichte hinüberrettet. Noch vor der Kehre hatte die Angst angesichts der eigenen Sterblichkeit die Funktion, das von der Welt isolierte Subjekt, das solus ipse, in ein emphatisches Selbstverhältnis zu bringen, auf dessen Grundlage es sich zu einer «eigentlichen〉 Existenz entschliessen kann. Diese Funktion taucht in den späteren, besonders in den politisch hoch bedenklichen Schriften wieder auf, ohne dass aber von der Angst die Rede ist. Denn das Vorlaufen auf ein seinsgeschichtliches Ende hin konfrontiert die Menschheit abermals mit sich selbst - eine Konfrontation, aus der sie eine eigentliche Existenz erwählen kann, um so dem drohenden Untergang etwas entgegenzuhalten. Das Problem dabei: Die Angstfunktion vereinzelt nun nicht mehr ein Subjekt, sondern, darüber lässt die Rektoratsrede von 1933 keine Zweifel aufkommen, das deutsche Volk.

«Eine geistige Welt allein verbürgt dem Volke die Grösse. Denn sie zwingt dazu, dass die ständige Entscheidung zwischen dem Willen zur Grösse und dem Gewährenlassen des Verfalls das Schrittgesetz wird für den Marsch, den unser Volk in seine künftige Geschichte angetreten hat.» (Heidegger 2000, 112)

Tatsächlich ist von der Angst nicht mehr die Rede. Doch ihre Eigentlichkeitsfunktion versieht auch in der neuen Seinsgeschichte unbeschadet ihren Dienst - mehr noch: Sie radikalisiert sich politisch zu einer Erwählungsfunktion.

Für die ursprüngliche Angst, die in Sein und Zeit ihren Sitz noch in einem Subjekt hatte, bedeutet der Umbau des individuellen Seins zum Tode hin zu einer kollektiven Untergangsgeschichte letztlich ihre Verwandlung in ein Gespenst. Sie schaltet und waltet, doch man sieht durch sie hindurch. Und doch 
macht sie sich auch nach Heideggers Wirken immer wieder bemerkbar: nämlich immer dann, wenn angesichts eines drohenden Untergangs sich jemand, etwas oder ein ganzes Volk selbst erwählt.

\subsubsection{Die Entdeckung der Angst}

Heideggers Werk Sein und Zeit ist ein philosophischer Apparat kolossalen Ausmasses. Sein Aufbau, seine Verdrahtung und seine Funktionsweise sind derart eigensinnig, dass Heidegger ihn selbst nicht mehr fertigzustellen vermochte. Der angekündigte zweite Teil fehlt und lässt sich auch aus nachfolgenden Schriften nicht rekonstruieren. Trotzdem schaffte es Sein und Zeit, gerade in Frankreich das existenzphilosophische Feuer zu entzünden. JeanPaul Sartres Das Sein und das Nichts (1943) erinnert nicht nur in der Titelgebung an die deutsche Fundamentalontologie. Dieser setzt der französische Grossstadtintellektuelle eine «phänomenologischen Ontologie» entgegen, die weniger deutsche Entschlossenheit als vielmehr französische Freiheit als Lebensziel betont. Maurice Merleau-Pontys Phänomenologie der Wahrnehmung (1945) wiederum übernimmt Heideggers Begriff des In-der-Welt-Seins, um dem Körper zu seinem philosophischen Recht zu verhelfen. Von Foucault und Derrida soll hier noch gar nicht die Rede sein.

An der Rezeption Heideggers lässt sich à la bande ablesen, was sein Frühwerk von der philosophischen Tradition eines Kant oder Descartes abhebt. Insbesondere die Verankerung des Subjekts in der Welt war jene Denkfigur, die den Transport auch über die deutsch-französische Grenze hinweg überstand. Um zu verdeutlichen, dass kein Subjekt mehr einem Objekt gegenübersteht, sondern es sich mitten in einem riesigen Geflecht von Objekten vorfindet, tauscht Heidegger das Vokabular aus. Aus dem Subjekt wird das «Dasein» und aus den Objekten wird «Zuhandenes». Der Mensch betrachtet nicht mehr wie im Museum die ruhenden Gegenstände an der Wand, sondern versucht, sich im Gewusel und Gedrängel mühsam zurechtzufinden. Er ist in eine unübersichtliche Gemengelage von Räumen, Treppen, Strassen, Städten, Hämmern und Nägeln seit Geburt an hineingeworfen - eine Gemengelage, die ihm nie nur ein Objekt in totaler Isolation präsentiert.

Um den Menschen in der See der Dinge nicht ertrinken zu lassen, gibt Heidegger dem Dasein, das die französische Philosophie im Begriff der Existenz rezipieren wird, eine reflexive Wendung. Der Mensch ist kein Ding und auch kein Tier, das sich von anderen Dingen oder Tieren hinsichtlich eines oder mehrerer Merkmale unterscheidet - sei es durch Vitalität oder Rationalität. Der Mensch ist vielmehr etwas, dem es in seinem Existieren um seine Existenz geht. Oder in Heideggers Terminologie: 
«Das Dasein ist ein Seiendes, das nicht nur unter anderem Seienden vorkommt. Es ist vielmehr dadurch ontisch ausgezeichnet, dass es diesem Seienden in seinem Sein um dieses Sein selbst geht.» (Heidegger 1993, 12)

Der Mensch steht demzufolge nicht nur in einem innigen Verhältnis zu den ihn umgebenden Dingen, sondern auch in einer tiefen Beziehung zu seiner eigenen Existenz. Gemeint ist damit nicht das schiere Überleben, vielmehr ein qualifiziertes Leben - das Leben, das man sich als das eigene zurechnet, zu dem man irgendwie Sorge trägt und das man irgendwie zu verwirklichen sucht.

Aus diesen beiden Beziehungspolen - der Welt auf der einen, der eigenen Existenz auf der anderen Seite - gewinnt Heidegger für das Dasein ein Spannungsverhältnis, das er in der einen Vereinseitigung als uneigentlich abwertet, in der anderen als eigentlich begrüsst.

Verfällt das Dasein an die Welt und die Mitmenschen, veruntreut es seine eigene Existenz und entfremdet sich von seinem eigentlichen Leben. Das Dasein gerät unter die entlastende, aber hartnäckige Herrschaft eines anonymen Man, das den Einzelnen mit seiner durchschnittlichen Alltäglichkeit beruhigt (Heidegger 1993, 127f.). Vernachlässigt das Dasein hingegen die Welt zugunsten seiner eigenen Verwirklichung, droht es, so möchte man meinen, im Labyrinth seiner selbst verloren zu gehen. Nicht so bei Heidegger. Denn dieser verteilt, wie bereits angedeutet, seine Sympathiepunkte überaus parteiisch auf den fremden Welt- und den eigenen Seinsbezug. Für den ehemaligen Messnerbub ist letztlich die Beziehung zu den Mitmenschen und Mitdingen in einer fast barock anmutenden Weise verzichtbar - und das, obwohl er der Analyse der Welt und den Dingen einen weitaus grösseren Platz einräumt als dem eigentlichen Seinsbezug. Fast verzweifelt sucht Heidegger deshalb nach Lücken, in denen der Mensch ausschliesslich mit sich selbst konfrontiert ist. Die Angst ist eine solche Lücke. Und hier nistet sich Heideggers kryptonormatives Pathos des eigentlichen Daseins ein. Unterm Strich gerät der Alltag unter einen Sinnlosigkeitsverdacht, während psychische Ausnahmezustände mit der ganzen Hoffnung auf einen eigentlichen Sinn überhäuft werden ...

Mehr als ein Jahrzehnt vor Adorno noch wird Hannah Arendt diese Asymmetrie zwischen einem oberflächlichen Welt- und einem ekstatischen Selbstbezug bemerken und korrigieren. In ihrem Werk Vita activa oder Vom tätigen Leben (2002 [1958]) setzt sie zum einen Heideggers Mortalitätssinnen ein Natalitätsdenken entgegen. Zum anderen hebt sie das gemeinschaftlich agierende zoon politikon in den Vordergrund, das arbeitend, herstellend und 
handelnd die Welt verändert, anstatt sich von ihr in Angst und Todesantizipation auf einen letztlich leeren Kern eines eigentlichen Selbst zurückzuziehen.

Filtert man Heideggers Eigentlichkeitssehnsucht als störendes Hintergrundgeräusch heraus - zumindest vorerst - und konzentriert sich stattdessen auf den aufwendigen Angstdetektor in Sein und Zeit, stellt sich abermals die Frage, was diese Apparatur mit Blick auf eine sich formierende Zukunftsangst zu entdecken, was zu erfinden in der Lage ist.

Die individuierende und isolierende Kraft der Angst gehört genauso wie ihr ausgeprägter Zukunftsbezug zu jenen Entdeckungen, die das 20. Jahrhundert als Zeitalter der Individualisierung bestätigen wird. Möglicherweise formuliert Sein und Zeit zum ersten Mal einen vertieften Zusammenhang zwischen Vereinzelung und Verängstigung. Es handelt sich um einen Konnex, der mit und nach dem Zweiten Weltkrieg von unterschiedlichen Individualisierungstheorien ebenfalls diagnostiziert werden wird - Theorien, die von Norbert Elias' Über den Prozess der Zivilisation (1939) und David Riesmans The Lonely Crowd (1950) über Ulrich Becks Risikogesellschaft (1986) bis hin zu Zygmunt Baumans Moderne und Ambivalenz. (1992) reichen.

Wie dem auch sei: Die Einsicht in die Isolationshaft der Angst stand für Kierkegaard und Freud noch nicht bereit. Kierkegaards Urszene setzt den isolierten Menschen Adam lediglich voraus, ohne dessen Vereinsamung theoretisch einholen zu können. Auch Freuds Strukturmodell lässt aufgrund der Statik von Ich, Über-Ich und Es keine zusätzliche Isolierung des Ichs zu. Allererst die Denkfigur eines immer schon in die Welt «geworfenen» Subjekts ermöglicht es, dessen ängstlichen Rückzug aus ihr begreifbar zu machen.

Induziert man im Experimentalsystem von Sein und Zeit einen Anfall der Angst, zerfällt dieser analytisch betrachtet in zwei Episoden. In einem ersten Schritt verliert die Welt jegliche Bedeutung, sodass es grundsätzlich nichts mehr gibt, wovor man sich ängstigen müsste. Lediglich die Furcht ist imstande, sich vor etwas Konkretem zu fürchten. Der Angst aber bleibt, wie bei Kierkegaard, bloss das Nichts.

«Die innerweltlich entdeckte Bewandtnisganzheit des Zuhandenen und Vorhandenen ist als solche überhaupt ohne Belang. Sie sinkt in sich zusammen. Die Welt hat den Charakter völliger Unbedeutsamkeit. In der Angst begegnet nicht dieses oder jenes, mit dem es als Bedrohlichem eine Bewandtnis haben könnte.» (Heidegger 1993, 186)

In einem zweiten Schritt isoliert die Angst das Subjekt von der belanglosen Welt und konfrontiert es mit sich selbst. «Die Angst vereinzelt und erschliesst so das Dasein als «solus ipses.» (Heidegger 1993, 188) Insofern die Dinge im 
Griff der Angst ihren nötigenden oder auffordernden Charakter verlieren keine Zimmer sind mehr aufzuräumen, keine Geschenke zu besorgen und keine Telefonanrufe zu tätigen -, eröffnet sich in der Angst letztlich eine schwindelerregende Freiheit, die an jene Kierkegaards erinnert. Der Wegfall eines jeden weltlichen Zwangs und jeder sozialen Verpflichtung mündet in ein Meer der Möglichkeiten.

«Die «Welt vermag nichts mehr zu bieten, ebensowenig das Mitsein Anderer. Die Angst benimmt so dem Dasein die Möglichkeit, verfallend sich aus der «Welt und der öffentlichen Ausgelegtheit zu verstehen. Sie wirft das Dasein auf das zurück, worum es sich ängstigt, sein eigentliches In-der-Welt-sein-können.» (Heidegger 1993, 187f.)

Im Vergleich zu Kierkegaards Angst, die vor allem um das Problem kreist, welche der zig gebotenen Möglichkeiten für ein Subjekt zur Wirklichkeit werden soll, radikalisiert Heideggers Variante den Zukunftsbezug. Denn in Sein und Zeit erfasst die Angst auch die Möglichkeit des eigenen Todes, die Möglichkeit des Nicht-mehr-sein-Könnens. Wie keine andere Befindlichkeit vermag es die Angst, die eigene Existenz in all ihren Möglichkeiten und Beschränkungen erfahrbar zu machen - allerdings zu einem hohen Preis. Denn begreifbar wird das eigene Leben nur von seinem Ende her.

Spätestens an diesem Punkt erhebt sich die Frage, wie sehr Sein und Zeit die Angst konstruiert, die sie zu entdecken vorgibt. Interessanterweise hält die Geschichte einen Test bereit, mit dem sich ermessen lässt, ob Heideggers Angst einem sich formierenden Gefühl im frühen 20. Jahrhundert entspricht oder bar jeder emotionalen Grundlage nur eine Lücke in einem philosophischen System schliesst. Die fragliche Prüfung gilt vordergründig nicht der Angst, sondern dem Ekel - ein Gefühl, dem Jean-Paul Sartre 1938 den Roman Der Ekel [franz. La Nausée] widmet. Um es vorwegzunehmen: Sartres Ekel entspricht in so vielen Hinsichten Heideggers Angst, dass beide als Belege für eine Emotionalität infrage kommen, die für ihre Existenz nicht mehr nur auf das Medium der Schrift angewiesen ist.

In Sartres Ekel dokumentiert der Erzähler, Antoine Roquentin, mithilfe von Tagebucheinträgen minutiös seine Innenwelt und deren Veränderungen. Wenngleich diese romanhafte Selbsterkundung nicht in philosophisch generalisierender, sondern künstlerisch konkretisierender Absicht erfolgt, erinnert sie nicht zufällig an die von Husserl propagierte, von Heidegger praktizierte Phänomenologie des Bewusstseinsstroms. Jedenfalls überfällt der Ekel Roquentin in steigendem Ausmass. Es beginnt bei der Berührung bestimmter Gegenstände, steigert sich zum Widerwillen gegenüber Mitmenschen und 
endet im tiefsten Ekel vor der eigenen lächerlichen Existenz. Mit jedem Schritt entfernt und entfremdet sich Roquentin von der physischen und sozialen Welt. Die Welt sinkt in sich zusammen und hinterlässt ein im Ekel isoliertes Subjekt. Wie Heideggers Angst ermöglicht aber auch Sartres Ekel die Einsicht in all das, was nicht sein muss, sondern was sein kann - letzten Endes in die Freiheit, die sich ob der Kontingenz all dessen, was existiert, auftut.

«Das Wesentliche ist die Kontingenz. Ich will sagen, dass die Existenz ihrer Definition nach nicht die Notwendigkeit ist. Existieren, das ist dasein, ganz einfach [...]. Es gibt Leute, glaube ich, die das begriffen haben. Nur haben sie versucht, diese Kontingenz zu überwinden, indem sie ein notwendiges und sich selbst begründendes Sein erfanden. Doch kein notwendiges Sein kann die Existenz erklären; die Kontingenz ist kein Trug, kein Schein, den man vertreiben kann; sie ist das Absolute, folglich die vollkommene Grundlosigkeit. Alles ist grundlos, dieser Park, diese Stadt und ich selbst.» (Sartre 1975, 149)

In mindestens vier Hinsichten gleichen sich Angst und Ekel. Erstens entziehen sie sich der Kontrolle und dem Willen des Subjekts, da sie sich plötzlich, überfallartig, ja monströs zeigen. Zweitens isolieren und individuieren sie den Menschen, indem sie ihm die Welt und die Mitmenschen abspenstig machen. Drittens haben beide Stimmungen einen erkennenden Charakter, insofern sie die Welt oder aber das Ich in einem neuen Licht erscheinen lassen. Und viertens erschliessen sie beide die Kontingenz und Freiheit des Subjekts, indem sie alle notwendigen Gründe und Fundamente der Existenz suspendieren.

In einem Aspekt jedoch weicht Heideggers Angst von Sartres Ekel ab. Denn dieser begreift den Möglichkeitsraum des eigenen Daseins nicht vom Ende bzw. vom künftigen Tod her, sondern lässt ihn mitten in den Alltag und die Gegenwart hereinplatzen. Roquentin erfährt von der Beliebigkeit seiner Existenz nicht etwa im Angesicht des Todes, sondern beim Anblick der Wurzel eines Kastanienbaumes im Park.

«Also, ich war gerade im Park. Die Wurzel des Kastanienbaums bohrte sich in die Erde, genau unter meiner Bank. [...] Ich sass da, etwas krumm, den Kopf gesenkt, allein dieser schwarzen und knotigen, ganz und gar rohen Masse gegenüber, die mir angst machte. Und dann habe ich diese Erleuchtung gehabt.» (Sartre $1975,144)$

Sartres Ekel lässt jenen Zukunftsbezug vermissen, der sowohl Heideggers als auch Freuds Angst als zeitlich akzentuierte Befindlichkeit auszeichnet. Und 
trotzdem: Zeigt man sich grosszügig hinsichtlich der abweichenden Benennung und orientiert man sich an den mehr als zufälligen Gemeinsamkeiten, komm man schwer umhin, «Ekel» und «Angst» als austauschbare Namen für eine Emotionalität in Betracht zu ziehen, die im frühen 20. Jahrhundert im Seelenleben der Menschen zu resonieren beginnt. Man hat es mit einer Kontingenzangst zu tun, die, ganz im Gegensatz zu Kierkegaard und Freud, nun auch die Möglichkeit, nicht zu existieren, umfasst. Der feine Unterschied besteht lediglich in der Attribution der Kontingenzerfahrung: Bei Sartre stammt sie aus der Gegenwart, bei Heidegger aus der Zukunft.

Was den Zukunftsbezug der Angst bei Heidegger zusätzlich plausibel macht, ist ihre Verwandtschaft mit der Sorge. Sie agiert in Sein und Zeit als das Scharnier, das die beiden grossen Themenkomplexe Existenz und Zeitlichkeit zusammenhält. In diesem Kontext taucht der Mensch nicht als ein behavioristisches Reiz-Reaktions-Tier auf, das auf die Stimuli der Welt, in die er geworfen wurde, lediglich reagiert. Vielmehr entwirft das Subjekt sich aus der Faktizität der Welt in die Zukunft hinaus, indem es Pläne schmiedet, Projekte verfolgt, Versprechen hält, Wetten abschliesst oder für einen Bildungsabschluss büffelt. In all diesen Tätigkeiten überholt das Subjekt seinen gegenwärtigen Zustand und sucht ihn auf einen künftigen hin zu verändern: «das Dasein ist ihm selbst in seinem Sein je schon vorweg» (Heidegger 1993, 191).

Indem das Subjekt Einkäufe besorgt, fürsorglich zu seinen Mitmenschen ist und zu sich selbst Sorge trägt, lebt es unweigerlich in der Zukunft. Und tatsächlich: Dank der Sorge, die Heidegger zum «Strukturganzen des Daseins» (a. a. O., 180) adelt, erhält man eine Idee davon, inwiefern das Bewusstsein seiner eigenen Existenz von einem Sinn der Zeitlichkeit, besonders der Zukünftigkeit getragen und getaktet ist. Selbst dann, wenn man dem Todesbezug der Angst nicht beipflichtet - sei es, weil eine Generalisierte Angststörung keine Todesangst impliziert, sei es, weil das Vorlaufen zum Tod zu viel Eigentlichkeit abverlangt -, kommt die temporale Verwandtschaft von Sorge und Angst glaubwürdig daher. In beiden Stimmungen entwirft sich das Subjekt auf künftige Situationen hin, die mindestens als herausfordernd gelten dürfen.

Die psychologische und psychiatrische Praxis bestätigt den Konnex zwischen Angst und Sorge. Das Therapiebuch Generalisierte Angststörung (Becker/Margraf 2014, 13f.) etwa identifiziert die entsprechende Angst anhand von Patienten, bei denen Sorgen im Mittelpunkt ihres Lebens stehen. Sorgen gelten den Autoren als «Gedankenketten», die «auf zukünftige Ereignisse gerichtet sind» und sich so «vom vergangenheitsorientierten Grübeln der Depressiven abgrenzen» lassen. Wer unter einer Generalisierten Angststörung 
leide, sei nicht mehr in der Lage, diese zukunftsgerichteten Sorgen zu kontrollieren - mit dem Effekt, dass die aussichtslose Beschäftigung mit ihnen mitunter 15 Stunden pro Tag einnehme.

Kurzum, Heideggers Frühwerk Sein und Zeit schafft es trotz seines zumutungsreichen Begriffssystems eine Emotion zu isolieren, die in vielen Punkten jene zeitlich ausdifferenzierte Angst vorwegnimmt, die als Zukunftsangst in den 1970er-Jahren zu einer steilen Karriere in Büchern, als Generalisierte Angststörung zu grosser Verbreitung in Psychen ansetzt. Es sind mehrere Gründe, die einen davon überzeugen, dass in der existenzphilosophischen Apparatur tatsächlich ein chronophobischer Fakt und nicht nur ein Artefakt hängen blieb.

Erstens zeichnet Heideggers Angstanalyse in grosser Übereinstimmung sowohl mit Sartres Ekel als auch mit dem psychopathologischen Alltag von heute die isolierende Kraft der Angst nach. Die in der Angst erfahrbare Isolierung und Abspaltung von der Welt und ihren Menschen entspricht dabei weniger einem Rückzug des betroffenen Menschen infolge einer Sozialen Phobie als vielmehr der Erfahrung einer Depersonalisation. Darunter verstehen die internationalen Klassifikationsschemata wie ICD-10 oder DSM-5 Erfahrungen von Patienten, die über ein «Gefühl von entfernt sein, von «nicht richtig hier» sein» klagen.

Zweitens deutet die in Sein und Zeit detektierte Angst auf die Erfahrung einer tief greifenden Kontingenz hin - eine Erfahrung von der Brüchigkeit und Unwirklichkeit der Welt, die auch Sartre für seinen Ekel in Anspruch nimmt. Allerdings bricht in beiden Stimmungen nicht nur die Welt in ihrer Bedeutung, sondern auch die eigene Existenz in ihrer Selbstverständlichkeit zusammen. Sie wird mit einem Mal als fragwürdig, wenn nicht hypothetisch erfahren - im radikalen Fall gar als Möglichkeit der Nichtexistenz begriffen.

Drittens kommt in Heideggers Frühwerk die Angst endlich auf die Zukunft zu liegen. Zwar hat schon Freuds neurotische Angst sich an künftigen Ereignissen festgebissen, doch die Ursachen der Angst vermutete Freud in vergangenen Traumata. Heidegger schafft es, mithilfe der Sorgestruktur einerseits und des wie immer bevorstehenden Todes andererseits der Angst endlich ihren Platz in der Zukunft zu sichern.

\subsubsection{Die Erfindung der Angst}

Sicherlich, Sein und Zeit hat mithilfe eines teilweise fragwürdigen Apparates eine Zukunftsangst freigelegt, deren Existenz die darauffolgenden Jahrzehnte immer wieder bestätigen werden. Nur hat diese Entdeckung eine Erfindung 
mitverschuldet, die ausgerechnet heute, im Jahr 2018, politisch zu neuem Leben erweckt wird.

Ungleich Freud hat sich Heidegger der Angst nie nur mit einem distanziert diagnostizierenden Ethos genähert. Im Gegenteil. Die entdeckte Zukunftsangst war eine willkommene Gelegenheit, an ihr ein Eigentlichkeitsdenken als Therapieform auszutesten, die zunächst als existenzphilo-sophisches Besinnungsprogramm durchging und als solches auch bei Sartre u. a. rezipiert wurde. Unglücklicherweise hat Heidegger wenig später sein Therapieangebot kollektiviert und das deutsche Volk zum ersten Patienten erkoren, das aus der Konfrontation mit der Angst kgeheilt hervorgehen sollte. Kurzum, Heidegger war nie daran gelegen, eine Zukunftsangst bloss zu identifizieren. Sie stand für ihn immer in einem therapeutischen Kontext, der zwar noch verborgen, dennoch merklich schon in Sein und Zeit erste politische Züge trug.

Der heuristische Unterschied zwischen Diagnose und Therapie hilft, den schmalen Grat zwischen einer entdeckten und einer erfundenen Zukunftsangst ausfindig zu machen. Erstens: Die isolierende Kraft der Zukunftsangst ist, wie bereits erwähnt, auch ein psychologisch gut dokumentiertes Phänomen. Dass hingegen diese zermürbende Isolation je in ein erhabenes Gefühl der Entschlossenheit oder gar des Erwähltseins münden könnte, gehört zu einer Therapiefiktion, die an Überheblichkeit gegenüber dem Leiden von Angstpatienten kaum zu übertreffen ist. Das psychische Leid lässt sich mit dem Hinweis auf Erwählung lindern. Zweitens: Dass eine Zukunftsangst sich ihre raison d'être von all dem geben lässt, was unter de futuris contigentibus firmiert, ist unstrittig. Dass sie sich aber allererst am eigenen Tod oder am kollektiven Untergang entzündet, ist ebenso eine Vereinseitigung, die der Aussicht auf ein zweifelhaftes therapeutisches Angebot geschuldet ist. Nota bene, Menschen mit einer Generalisierten Angststörung sorgen sich in den meisten Fällen weit mehr um ihre Angehörigen als um sich selbst. Es scheint, als ob diesen Patienten weit mehr am Überleben der Mitmenschen als an ihrem eigentlichen Vorlaufen zum Tode gelegen ist.

Vor wenigen Jahren hat der renommierte Erziehungswissenschaftler Micha Brumlik (2016) die Rezeption von Heideggers Werk bei den intellektuellen Gewährsmännern der Neuen Rechten nachgezeichnet. Hierbei stiess er auf ein brisantes Detail: Nicht erst der spätere Heidegger, der die Schwarzen Hefte und deren antisemitische und menschenverachtende Inhalte zu verantworten hat, gelangte in den Lesehorizont identitärer Denker. Nein, bereits das Frühwerk Sein und Zeit erhielt für seine zwar gut kaschierten, aber nicht minder völkischen Bemerkungen rechten Zuspruch, so etwa von Alexander 
Dugin, einem Neofaschisten und Vordenker der Neuen Rechten in Russland. Selbst dann, wenn man in diesem undurchsichtigen Werk erst gar nicht auf die ominösen Zeilen in Paragraf 74 stösst, bleibt man an einer Verstrickung von Untergangs- und Eigentlichkeitsmotiven hängen, die gleichermassen politische und religiöse Züge trägt. Dieser «Verhängniskomplex überlebt nicht nur Heideggers viel beschworene Kehre, sondern spitzt sich ausgerechnet zu jenem Motiv zu, das die tiefe Komplizenschaft zwischen Heideggers Philosophie und dessen nationalsozialistischem Engagement begründet.

Bereits im Frühwerk formuliert der besagte Komplex eine Chronopolitik, die angesichts des sicheren Todes dem Subjekt eine Haltung der Entschlossenheit abverlangt. An den Strukturen dieses Verfallsdenkens wird Heidegger auch später noch festhalten, selbst wenn er einzelne Variablen mit neuen Werten versieht: Der bevorstehende Individualtod wird durch einen kollektiven Untergang ersetzt, den Heidegger dem Untergang des Abendlandes von Oswald Spengler (1991 [1918]) entlehnt, aber noch tiefer und eigentlicher denken möchte. Die individuelle Entschlossenheit aus Sein und Zeit wiederum macht Platz einer kollektiven Selbsterwählung angesichts des drohenden Abgrundes. Müssig zu erwähnen: Es ist das deutsche Volk, das im Augenblick der äussersten Not sich in einer Art Aufopferung zum neuen Anfang wählt. Das belegt unzweideutig jene Sentenz, die Heidegger den Schwarzen Heften aus den Jahren 1938/39 voranstellte:

«Deutsch sein: die innerste Last der Geschichte des Abendlandes vor sich her werfen und auf die Schulter nehmen.» (Heidegger 2014, 1)

Anders als Sartres Ekel ging es Sein und Zeit nie darum, lediglich eine Emotionalität freizulegen und als Phänomen sui generis zu studieren. Heideggers Angst ist ganz dem therapeutischen Ziel untergeordnet, aus der Konfrontation des Subjekts mit sich selbst einen geläuterten und gestärkten Menschen hervorgehen zu lassen, der dem Tod entschlossen ins Auge blickt. Der Angst kommt die Funktion einer Katharsis zu, die das Dasein von seiner Verfallenheit an den Alltag und die Mitmenschen reinigt und ihm die Möglichkeit der eigenen Nichtexistenz offeriert. Im O-Ton:

«Mit der nüchternen Angst, die vor das vereinzelte Seinkönnen bringt, geht die gerüstete Freude an dieser Möglichkeit zusammen. In ihr wird das Dasein frei von den 〈Zufälligkeiten〉 des Unterhaltenwerdens [...]» (Heidegger 1993, 310)

Nicht nur Arendt blieb schleierhaft, was der Gewinn einer angsterfüllten Entschlossenheit, was der Mehrwert einer solch eigentlichen Existenz sein sollte. Sicherlich, die Besinnung auf den eigenen Tod mag für einen Moment 
einen «rüstigen〉 Dezisionismus freisetzen - doch allein die Betonung von Tat und Handlung reicht nicht aus, dem Dasein eine Richtung zu geben. Aufgrund dessen bleibt die Entschlossenheit eine Leerformel, die zwar eine Art Seinsbewegung oder Existenzmotion verspricht, aber jede Antwort auf die Frage «Was soll ich tun?» schuldig bleibt.

Nach Sein und Zeit verliert die Angst ihren Platz im Herzen des Daseins. Heidegger suchte fortan jede Subjektivitätsphilosophie zu überwinden, die entfernt noch an einen Humanismus erinnerte. Und um diesen endgültig hinter sich zu lassen, wählte Heidegger eine Flughöhe, von der aus er die gesamte Geschichte der Metaphysik überblicken und ihr einen tiefen Fall prophezeien konnte. Denn aus dem Verhängnis, das mit Platon seinen Anfang nahm und das im Gestell der Technik kulminieren sollte, führt grundsätzlich kein Weg heraus. Grundsätzlich. Denn für die höchste Not konstruierte Heidegger einen Schleudersitz, der einen aus dem abstürzenden Metaphysikjet in eine andere Sphäre hinauskatapultiert - eine Sphäre, in der sich alles auf eine ganzheitliche Art lichtet. Wer hier Esoterik vermutet, liegt richtig. Denn diese Sphäre ist nur den Erben eines deutschen Dichtens und Denkens vorbehalten, die zu würdigen wissen, dass sich die 〈Wahrheit des Seins〉 nicht nur in Form naturwissenschaftlicher Erkenntnisse oder technischer Errungenschaften «entbirgt).

Mit Begriffen wie Seinslichtung, Entbergung oder Gestell bedient sich Heidegger weit mehr als nur einer esoterischen Sprache, die von Edelsubstantiven durchwirkt ist. Mit der Drohung eines Untergangs des Abendlandes forciert Heidegger zugleich eine Rettungsphantasie, die wie jene der Arche Noah nur wenige Auserwählte, aber Tausende, wenn nicht Millionen gesichts- und geschichtsloser Menschen in Kauf nimmt, die «einfach so〉 dem Untergang anheimgegeben werden. Wer hier die aus Sein und Zeit übernommene Denkstruktur im Blick behält, erkennt in all jenen, die dem Untergang aus schlichtem Vergessen überlassen werden, jenes «unentschlossene> Dasein aus Sein und Zeit, das dem Man, der Alltäglichkeit und dem Gerede verfiel. Ihm gegenüber steht das entschlossene Selbst, das nach der Kehre als deutsches Volk dem Untergang ins Auge blickt, die «Geschichte des Abendlandes schultert und dafür mit einem Fluchtausgang in den Hinterhof der Metaphysik belohnt wird.

Der Verhängniskomplex, wie er sich nach Sein und Zeit artikuliert, ist auf die Angst, diesen Sinn für Kontingenz, Zukunft und Freiheit, nicht mehr angewiesen. Und doch organisiert die Angst gespensterhaft weiterhin ein Denken, das den eigenen Tod zum Untergang des Abendlandes generalisiert, 
das die individuelle Entschlossenheit zur völkischen Auserwählung kollektiviert und das die subjektive Verfallenheit an das Man mit dem Untergang des Abendlandes gleichstellt.

Die Angst entpuppt sich in Heideggers späterem Denken als ein Strukturelement, mit dem sich auf bedenkliche Art und Weise drei Dinge zusammendenken lassen: Untergang, ehemals: Tod; Auserwählung, ehemals: Entschlossenheit; Opferung und Rettung, ehemals: Vorlaufen zum Tod. Vielleicht, so die Hoffnung, lässt sich anhand dieser sezierten Struktur eine Warnung aussprechen: Wann immer in öffentlichen Diskursen entweder Kollektive Ängste in Anspruch nehmen oder aber Ängste auf Kollektive attribuiert werden, ist exakt zu prüfen, wie kurz die Distanz zwischen Angst und Entschlossenheit und wie gross die Nähe zwischen vermeintlichem Untergang und Ermächtigung zum Handeln ist.

\subsubsection{Heideggers Angst}

Mit seinem Strukturmodell der Psyche gelang Freud eine Differenzierung der Angst, die sich im Ergebnis weitgehend mit der These dieses Beitrages deckt: Die Angst habe sich im Laufe der Zeit in drei unterschiedliche Sinndimensionen ausdifferenziert. In die sachliche Dimension kommt Freuds Realangst zu liegen, in die soziale die Gewissensangst und in die zeitliche die neurotische Angst. An letzter Stelle aber hakte es noch: Freuds neurotische Angst wollte sich nie ganz in das historische Narrativ der Herausbildung einer Zukunftsangst einfügen.

Obgleich die gigantische Apparatur von Sein und Zeit nie dazu erfunden wurde, brachte sie es doch fertig, jene Zukunftsangst zu entdecken, deren Existenz das Ausdifferenzierungsschema nahelegt: 
Ausdifferenzierung der Angst (sachlich, sozial, zeitlich)

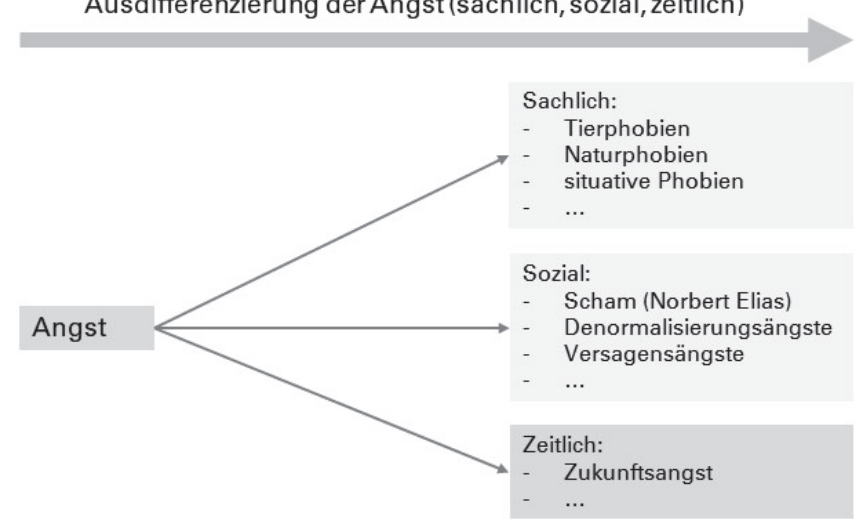

Abbildung 9: Die These (identisch mit Abbildung 2).

Konsultiert man zeitgenössische Diagnosen einer Generalisierten Angststörung, spricht einiges dafür, dass die von Heideggers Frühwerk erschriebene Angst nicht nur ein Artefakt eines umständlichen und teils verworrenen Denk- und Begriffsapparates ist, sondern mitunter eine Emotionalität trifft, die sich in den frühen Jahren des 20. Jahrhunderts gerade auszukristallisieren beginnt. Dass diese erst in statu nascendi begriffen ist, legt zudem Sartres Ekel nahe, der einem ähnlichen Emotion auf der Spur ist. Und dieses ist wie bei Heidegger in der Lage, den Menschen zu vereinzeln. Vor allem aber ist es imstande, das eigene Leben, das der Mitmenschen, ja die gesamte Welt in einen Nebel des Hypothetischen zu hüllen, in dem Selbstverständlichkeiten die Gestalt von Möglichkeiten annehmen. Diese schmerzliche Befähigung zur Kontingenzerkennung wird empirisch von Angstpatienten bestätigt, deren Sorgenkarusselle alltägliche Erwartungshaltungen suspendieren und in Gefahren verwandeln.

Fragwürdig bleibt nur, ob der Zukunftsbezug der sich hier formierenden Angst einem Vorlaufen zum Tod geschuldet ist. Heidegger behauptet dies. Eine andere mögliche Erklärung könnte sich auf kollektive Erfahrungen stützen, die mit der dunklen Seite der Zukunft im Ersten Weltkrieg gemacht wurden. 


\section{Gefühl, Gehirn und Geisteswissenschaft}

Woher kennen wir unsere Gefühle? Wie lernen wir, Trauer, Angst, Liebe oder Hoffnung auseinanderzuhalten? Nahezu alle Geisteswissenschaften eint in diesen Fragen ein interpretatives Paradigma: Bis auf wenige Ausnahmen wie Hunger, Durst und Schrecken ist alles, was wir fühlen und empfinden, abhängig von unserer Interpretation, Bewertung oder Beschreibung. Das schliesst physiologische Veränderungen des Körpers mitnichten aus: Wer verliebt ist, besitzt einen erhöhten Oxytocinspiegel mit allen angenehmen Nebenfolgen. Allerdings gilt das nicht vice versa. Wem dieses Hormon durch den Körper strömt, muss keineswegs verliebt sein. Und wer zittert und schwitzt, mag so Unterschiedliches wie freudige Erwartung oder abgrundtiefe Angst empfinden. Der Körper hinkt gewissermassen unseren Gefühlen hinterher. Und es ist diese physiologische Unterbestimmtheit, die den Geisteswissenschaften Tür und Tor öffnet. Mit Recht können sie auf die Sprache verweisen, die für die Interpretation unserer Gefühle allererst den nötigen Differenzierungsreichtum bereitstellt. Wie sehr wir uns an diese sprachlichen Nuancen in unserem Gefühlsleben angepasst haben, macht etwa ein Thesaurus klar. Wer nach «Trauer» blättert, erhält mindestens zehn Vorschläge, um seine Gefühle zu präzisieren und zu sortieren. Sie reichen von «Kummer» und «Betrübnis» über «Niedergeschlagenheit» und «Reue» bis hin zu «Trübsinn» und «Verzweiflung». Ein erwachsener Mensch ist für gewöhnlich imstande, allein bei der Lektüre dieser Wörter die semantischen Unterschiede nachzuempfinden. In seinen Philosophischen Untersuchungen zweifelte Wittgenstein gar an unserer Fähigkeit, Gefühle ohne Rekurs auf eine gemeinsame Sprache und deren Unterscheidungskriterien identifizieren zu können: «Ein innerer Vorgang bedarf äusserer Kriterien.» (1953, \580)

Auch dann, wenn wir uns den Gefühlen von der Physiologie her nähern, zeigt sich ebenso das Bild der Interpretationsbedürftigkeit von Gefühlen. In einem nachgerade klassischen Experiment haben Stanley Schachter und Jerome E. Singer (1962) Versuchspersonen Adrenalin injiziert, das die Sozialpsychologen jedoch als Vitamincocktail ausgaben. Die vom Hormon nun ordentlich geschüttelten Kandidaten und Kandidatinnen wurden in zwei Gruppen aufgeteilt, die daraufhin entweder in eine spielerisch-lustige oder eine ärgerliche Situation verwickelt wurden. Wer in letztere Lage geriet, musste einen langen Fragebogen mit teils übergriffigen Fragen ausfüllen, wer Glück hatte, wurde zu albernen Spielen aufgemuntert. Das Experiment sah also vor, physiologisch identische Erregungszustände zu schaffen, die Inter- 
pretation aber von eingeweihten Begleitpersonen abhängig zu machen, welche die Situationen entsprechend als lustig oder ärgerlich kommentierten. Tatsächlich schlossen sich die Versuchspersonen in der Deutung ihrer Gefühle den Angeboten an und gaben entsprechend Ärger oder Freude zu Protokoll.

Seit den Angst-Experimenten von Joseph E. LeDoux (1996) findet auch in den Neurowissenschaften die Interpretations- oder Kognitionsabhängigkeit von Gefühlen grossen Anklang. Liegt nicht gerade ein akuter Schrecken vor, der in ein sofortiges Fluchtverhalten mündet, nehmen furchteinflössende Reize nicht den direkten Weg über den Thalamus zur Amygdala, sondern machen einen Umweg über den Hippocampus sowie den präfrontalen Cortex. In Zusammenarbeit sorgen beide Hirnareale einerseits für die angemessene Kategorisierung sowie die Speicherung der Empfindung. Entscheidend ist hier der Hinweis auf die «Historizität) der beiden Regionen. Denn die Kategorisierung als auch die Memorierung des Reizes erfolgt auf der Grundlage bereits gemachter Erfahrungen.

Diese grundsätzlich anmutenden Bemerkungen am Ende einer anstrengenden Reise in die Unterscheidungsuntiefen von erfundener und entdeckter Zukunftsangst möchten tatsächlich zwei Punkte nochmals in Erinnerung rufen: Der erste ist methodologischer, der zweite sachlicher Natur.

Erstens. Geisteswissenschaftliche Texte eignen sich seit jeher für Geistergespräche. Die Lektüre der vermeintlich zeitlosen Weisheiten grosser Männer macht einen zu einem Gesprächspartner einer über Jahrhunderte währenden Diskussion, die darauf angewiesen ist, dass Platon, Aristoteles, Augustinus, Kant, Nietzsche und Heidegger - oder wie sonst die Gewährsmänner heissen mögen - noch am Leben sind, wenigstens durch ihre Schriften. Hin und wieder aber lohnt es sich, die Reihen der Geister zu lichten und hie und da einen Gedanken ehren- und würdevoll zu Grabe zu tragen. Das bedeutet keinesfalls, dass der Gedanke ausgelöscht und vergessen werden sollte. Gäbe es eine Gedankenethik, es wäre dies der erste Grundsatz: Kein Gedanke sollte je vergessen werden. Eine Beerdigung versetzt bloss einen Gedanken von einem lebendigen in einen toten Zustand. Mit diesem Akt wird er einer Zeit anheimgegeben, die nicht mehr die unsere ist. Der Gedanke wird im besten Sinne historisch. Er wird zu einer Antwort auf vergangene Probleme und Herausforderungen - eine Lösung, die wir beherzigt und verinnerlicht haben.

Eine Historisierung der Geisteswissenschaften in diesem Sinne ist ein erster Schritt, ihre Dokumente nicht als überzeitliche Wahrheiten, sondern als teils aufwendige Experimentalanordnungen zu begreifen, die zu ihrer Zeit 
eine Emotion wie die zunächst anomalisch wirkende Zukunftsangst einzufangen und zu studieren suchten. Michel Foucault $(1981,198)$ sprach einst davon, Dokumente in archäologische Monumente zu verwandeln, um zu hindern, dass sie immer wieder auf ihre tiefere Bedeutung hin befragt werden. Monumente sind keine Schatzkästen ewiger Wahrheiten, sondern Zeugen einer spezifischen Zeit, die nicht mehr die unsere ist. Diese Historisierung oder, wer will, diese Halbwertsverzeitlichung von Texten wird aufgewogen durch ihre Empirisierung. Selbst die selbstreferenziell wirkenden Opera von Kant u. a. sind keine Texte, die Begriffe definieren und sie ohne jeden Blick auf die Wirklichkeit hübsch und möglichst widerspruchsfrei arrangieren. Anders ausgedrückt: Auch die logischsten Theorien bestehen nicht nur aus Analytik. Sie enthalten so viel Synthetik, dass ihre Sätze und Theoreme bloss kontingent wahr sind.

Das gilt auch und besonders für die Angsttraktate von Kierkegaard, Freud und Heidegger. Sie alle erschreiben eine emotionale Wirklichkeit, die sie bisweilen auch selbst herstellen, die aber nicht mehr der des 21. Jahrhunderts entspricht. Kierkegaards taumelnd-sündige Angst ist nicht mehr die sorgenvolle heutiger Angstpatienten. Und Heideggers Angst um das eigentliche Seinkönnen erscheint angesichts der stressigen, aber mundanen Existenzsorgen von heute wie ein Anachronismus. Die Texte sind zu Monumenten geworden. Sie erinnern an verlassene Grossforschungseinrichtungen, in denen einstmals Ängste analysiert, studiert und synthetisiert wurden.

Zweitens: Besonders die Interpretationsbedürftigkeit von Empfindungen macht den Wandel von Gefühlen begreiflich. Neben Fernsehserien dürfte auch heute noch die Belletristik für die Ausbildung eines differenzierten Empfindungsapparates bei Jugendlichen und Erwachsenen sorgen. Es lässt sich darüber spekulieren, ob die grossen Romane der letztem zwanzig Jahre, zu denken wäre etwa an Houllebecqs Elementarteilchen (1998), Smith’ Zähne zeigen (2000) oder Frantzens Korrekturen (2001), ihren Leserinnen und Lesern nicht einen Reichtum an Ambivalenzempfindungen vermacht haben - Empfindungen, die im 19. Jahrhundert möglicherweise erst zu keimen begannen.

In diesem Beitrag wurde der Versuch unternommen, den Wandel eines Gefühls nachzuzeichnen. Mit einer modernisierungstheoretischen Brille auf der Nase, die einen ständigen Komplexitätszuwachs sehen will, ging es darum, einen Ausdifferenzierungsprozess in den Blick zu nehmen, der die Angst im Laufe der Zeit in immer feinere Teile zergliedert hat - in sachliche, soziale und temporale Ängste. 
Vor dem Hintergrund eines chronopolitischen Zeitalters, in dem die Zukunft zum Grund allen Handelns in der Gegenwart geworden ist, interessierte besonders die Frage, wie unser Gefühlshaushalt auf diese immer dominantere Zukunftsorientierung reagiert. Es lag also nahe, nach der Geburt einer Zukunftsangst zu fragen.

\section{Literatur}

Adorno, Theodor W. (1964): Jargon der Eigentlichkeit. Zur deutschen Ideologie, Frankfurt a. M.

Arendt, Hannah (2002): Vita activa oder Vom tätigen Leben. München/Zürich. Aron, Raymond (1968): Main Currents in Sociological Thought, Volume I: Montesquieu, Comte, Marx, Tocqueville, and The Sociologists and the Revolution of 1848, New York.

Balint, Michael (1972): Angstlust und Regression. Beitrag zur psychologischen Typenlehre, Reinbek b. H.

Bauman, Zygmunt (1992): Moderne und Ambivalenz, Hamburg.

Beck, Ulrich (1986): Risikogesellschaft. Auf dem Weg in eine andere Moderne, Frankfurt a. M.

Becker, Eni / Margraf, Jürgen (2014): Generalisierte Angststörung. Ein Therapieprogramm, Weinheim.

Brown, Timothy A. / O'Leary, Tracy A. / Barlow, David H. (32001): «Generalized Anxiety Disorder», in: David H. Barlow (Hg.): Clinical Handbook of Psychological Disorders, New York u. a.

Brumlik, Micha (2016): Das alte Denken der neuen Rechten. Mit Heidegger und Evola gegen die offene Gesellschaft, in: Blätter für deutsche und internationale Politik 3, 81-92.

Bude, Heinz (2014): Gesellschaft der Angst, Hamburg.

Burkeman, Oliver (2007): Days That Shook the World, in: The Guardian, April 28, Books, www.theguardian.com/books/2007/apr/28/society.

Bush, George W. (2002): President's Remarks. Graduation Speech at West Point United States Military Academy West Point., New York, www.usma. edu/classes2/SitePages/GradSpeech02.aspx.

Butcher, James N. / Mineka, Susan / Hooley, Jill M. (132009): Klinische Psychologie, München.

Cooper, Melinda (2008): Life as Surplus: Biotechnology and Capitalism in the Neoliberal Era, Seattle, http://public.eblib.com/choice/publicfullrecord. aspx?p=3444266. 
Delumeau, Jean (1989): Angst im Abendland. Die Geschichte kollektiver Ängste im Europa des 14.-18. Jahrhunderts, Reinbek b. H.

Derrida, Jacques (2002): Übergänge - vom Trauma zum Versprechen (Interview mit Elisabeth Weber), in: ders.: Auslassungspunkte. Gespräche, Wien, 377-398.

Duerr, Hans Peter (1988): Der Mythos vom Zivilisationsprozess, Bd. 1: Nacktheit und Scham, Frankfurt a. M.

Ehrenberg, Alain (2004): Das erschöpfte Selbst. Depression und Gesellschaft in der Gegenwart, Frankfurt a. M. / New York.

Elias, Norbert (1997a): Über den Prozess der Zivilisation. Soziogenetische und psychogenetische Untersuchungen, Bd. 1: Wandlungen des Verhaltens in den weltlichen Oberschichten des Abendlandes, Frankfurt a. M.

Elias, Norbert (1997b): Über den Prozess der Zivilisation. Soziogenetische und psychogenetische Untersuchungen, Bd. 2: Wandlungen der Gesellschaft. Entwurf zu einer Theorie der Zivilisation, Frankfurt a. M.

Foucault, Michel (1981): Archäologie des Wissens, Frankfurt a. M.

Freud, Sigmund / Breuer, Josef (1893): Über den psychischen Mechanismus hysterischer Phänomene, in: Neurologisches Centralblatt 1, 374.

Freud, Sigmund (1895): Über die Berechtigung, von der Neurasthenie einen bestimmten Symptomenkomplex als «Angst-Neurose» abzutrennen, in: Neurologisches Zentralblatt 14, 50-66.

Freud, Sigmund (2006a): Vorlesungen zur Einführung in die Psychoanalyse (1916-1917), in: ders.: Die Traumdeutung und andere Schriften 2, Frankfurt a. M., 711-1046.

Freud, Sigmund (2006b): Neue Folge der Vorlesungen zur Einführung in die Psychoanalyse, in: ders.: Die Traumdeutung und andere Schriften 2, Frankfurt a. M., 1047-1182.

Freud, Sigmund (2015): Hemmung, Symptom und Angst, in: ders.: Gesammelte Werke (Sämtliche Werke), elektronische Ausgabe, o. S.

Goede, Marieke de (2012): Speculative Security: The Politics of Pursuing Terrorist Monies, Minneapolis, http://site.ebrary.com/id/10555683. Heidegger, Martin (1993): Sein und Zeit (1927), Tübingen.

Heidegger, Martin (2000): Die Selbstbehauptung der deutschen Universität. Rede gehalten bei der feierlichen Übernahme des Rektorats der Universität Freiburg am 27. Mai 1933, Gesamtausgabe, Bd. 16, Frankfurt a. M. Heidegger, Martin (2006): Was ist Metaphysik? (1929), Frankfurt a. M. Heidegger, Martin (2014): Überlegungen VII-XI (Schwarze Hefte 1938/39), Gesamtausgabe, Bd. 95, Frankfurt a. M. 
Hermann, Martin (2015): A History of Fear. British Apocalyptic Fiction, 1895-2011, Berlin.

Hobbes, Thomas (1839): Thomae Hobbes Malmesburiensis Vita, Opera philosophica quae latine scripsit omnia in unum corpus nunc prima collecta studio et labore, Gulielmi Molesworth, Bd. 1, London.

Hölscher, Lucian (1999): Die Entdeckung der Zukunft, Frankfurt a. M.

Jonas, Hans (1984): Das Prinzip Verantwortung. Versuch einer Ethik für die technologische Zivilisation, Frankfurt a. M.

Kaiser, Mario (2015): Reactions to the Future: The Chronopolitics of Prevention and Preemption, in: NanoEthics 9 (2), 165-177.

Kierkegaard, Søren (1992): Der Begriff Angst, Stuttgart.

Kisch, Enoch Heinrich (1887): Die Nervenschwäche (Neurasthenie), in: Die Gartenlaube 1, 10-12.

Konermann, Jürgen / Zaudig, Michael (2003): Diagnostik und Differenzialdiagnostik der Angststörungen nach ICD-10, in: Psychotherapie 8 (1), 72-84. Laffan, Michael / Weiss, Max (Hg.) (2012): Facing Fear: The History of an Emotion in Global Perspective, Princeton NJ.

LeDoux, Joseph (1996): The Emotional Brain. The Mysterious Underpinnings of Emotional Life, New York.

Link, Jürgen (2006): Versuch über den Normalismus. Wie Normalität produziert wird, Göttingen.

Luhmann, Niklas (1976): The Future Cannot Begin: Temporal Structures in Modern Society, in: Social Research 43 (1), 130-153.

Merleau-Ponty, Maurice (1974): Phänomenologie der Wahrnehmung (1945), Berlin.

Propp, Vladimir Jakovlevič (1975): Morphologie des Märchens, Frankfurt a. M. Radkau, Joachim (1998): Das Zeitalter der Nervosität. Deutschland zwischen Bismarck und Hitler, München.

Riesman, David (2001): The Lonely Crowd, Revised edition: A Study of the Changing American Character (1950), Yale.

Robin, Corey (2004): Fear: The History of a Political Idea, New York.

Rosa, Hartmut (2013): Beschleunigung und Entfremdung. Entwurf einer Kritischen Theorie spätmoderner Zeitlichkeit, Berlin.

Rumsfeld, Donald (2002): Departement of Defense News Briefing Secretary Rumsfeld and Gen. Myers, Washington DC, http://archive. defense. gov/Transcripts/Transcript.aspx? TranscriptID $=2636$.

Sartre, Jean-Paul (1975): Der Ekel (1938), Reinbek b. H. Sartre, Jean-Paul (1993): Das Sein und das Nichts (1943), Hamburg. 
Schachter, Stanley / Singer, Jerome E. (1962): Cognitive, social, and physiological determinants of emotional states, in: Psychology Review 69, 379-399.

Spengler, Oswald (1991): Der Untergang des Abendlandes. Umrisse einer Morphologie der Weltgeschichte, 2 Bde., München.

Stearns, Peter N. (2006): Fear and Contemporary History: A Review Essay, in: Journal of Social History 40 (2), 477-484.

Stichweh, Rudolf (2006): Die Autopoiesis der Wissenschaft, in: ders. (Hg.): Wissenschaft, Universität, Professionen. Soziologische Analysen, Frankfurt a. M., 52-83.

Stichweh, Rudolf (2007): The Black Swan: The Impact of the Highly Improbable, New York.

Tanner, Jakob (2012): Historische Anthropologie, Version 1.0, Docupedia-Zeitgeschichte, http://docupedia.de/images/e/e8/Historische_Anthropologie. pdf.

Tocqueville, Alexis de. 1976. Über die Demokratie in Amerika. München

Watts, Michael (2013): A political ecology of environmental security, in: Floyd, Rita / Matthew, Richard (Hg.): Environmental Security: Approaches and Issues, New York, 82-100.

Wittgenstein, Ludwig (2001): Philosophische Untersuchungen, Kritischgenetische Edition, Frankfurt a. M.

Wodak, Ruth (2015): The Politics of Fear: What Right-Wing Populist Discourses Mean, London. 